\title{
Estrogen promotes estrogen receptor negative BRCA1-deficient tumor initiation and progression
}

\author{
Chuying Wang ${ }^{1,2}$, Feng Bai ${ }^{2 *}$, Li-han Zhang ${ }^{2}$, Alexandria Scott ${ }^{2}$ Enxiao $\mathrm{Li}^{1 *}$ and Xin-Hai Pei ${ }^{2,3^{*}}$ (D)
}

\begin{abstract}
Background: Estrogen promotes breast cancer development and progression mainly through estrogen receptor (ER). However, blockage of estrogen production or action prevents development of and suppresses progression of ER-negative breast cancers. How estrogen promotes ER-negative breast cancer development and progression is poorly understood. We previously discovered that deletion of cell cycle inhibitors p16 $6^{\operatorname{lnk} 4 a}$ (p16) or p18 ${ }^{\operatorname{lnk} 4 \mathrm{c}}$ (p18) is required for development of Brca1-deficient basal-like mammary tumors, and that mice lacking p18 develop luminal-type mammary tumors.
\end{abstract}

Methods: A genetic model system with three mouse strains, one that develops ER-positive mammary tumors ( $p 18$ single deletion) and the others that develop ER-negative tumors (p16;Brca1 and p18;Brca1 compound deletion), human BRCA1 mutant breast cancer patient-derived xenografts, and human BRCA1-deficient and BRCA1-proficient breast cancer cells were used to determine the role of estrogen in activating epithelial-mesenchymal transition (EMT), stimulating cell proliferation, and promoting ER-negative mammary tumor initiation and metastasis.

Results: Estrogen stimulated the proliferation and tumor-initiating potential of both ER-positive Brca1-proficient and ER-negative Brca1-deficient tumor cells. Estrogen activated EMT in a subset of Brca1-deficient mammary tumor cells that maintained epithelial features, and enhanced the number of cancer stem cells, promoting tumor progression and metastasis. Estrogen activated EMT independent of ER in Brca1-deficient, but not Brca1-proficient, tumor cells. Estrogen activated the AKT pathway in BRCA1-deficient tumor cells independent of ER, and pharmaceutical inhibition of AKT activity suppressed EMT and cell proliferation preventing BRCA1 deficient tumor progression.

Conclusions: This study reveals for the first time that estrogen promotes BRCA1-deficient tumor initiation and progression by stimulation of cell proliferation and activation of EMT, which are dependent on AKT activation and independent of ER.

Keywords: Estrogen, Estrogen receptor, BRCA1, EMT, Cancer stem cells

\section{Background}

Estrogen plays a critical role in promoting breast cancer development and progression in addition to normal breast development $[1,2]$. Although estrogen acts mainly through the estrogen receptor (ER), ovariectomy,

\footnotetext{
*Correspondence: fbai@med.miami.edu; doclienxiao@sina.com; xhpei@med.miami.edu

${ }^{2}$ Molecular Oncology Program, Division of Surgical Oncology, Dewitt Daughtry Family Department of Surgery, University of Miami, Miami, FL 33136, USA

'Department of Medical Oncology, The First Affiliated hospital of Xi'an Jiaotong University, Xi'an, Shaanxi 710061, People's Republic of China Full list of author information is available at the end of the article
}

blockage of estrogen action, or inhibition of estrogen synthesis can prevent the development of and suppress the progression of ER-negative breast cancers [3, 4]. In addition to stimulation of proliferation and induction of DNA damage in both ER-positive and ER-negative cells $[1,2]$, estrogen activates an epithelial-mesenchymal transition (EMT) program in ER-positive breast cancer cells to promote their stemness and invasiveness in vitro [5, 6]. Notably, it has recently been reported that estrogen promotes the number and function of ER-negative breast cancer stem cells (CSCs) through paracrine signaling produced in ER-positive cells in response to

(c) The Author(s). 2018 Open Access This article is distributed under the terms of the Creative Commons Attribution 4.0 International License (http://creativecommons.org/licenses/by/4.0/), which permits unrestricted use, distribution, and 
estrogen $[7,8]$. Whether and how estrogen promotes ER-negative breast cancer development and progression are poorly understood.

Breast cancer comprises, among others, three main subtypes: human epidermal growth factor receptor 2 (HER2)-positive, ER-positive luminal, and ER-negative basal-like breast cancers (BLBCs) [9]. Luminal-type tumors respond to hormone therapy. BLBCs are poorly differentiated and the most lethal, which is partly due to their enrichment of CSCs that are thought to drive clinical relapse and metastasis $[10,11]$. The CSCs can be generated from luminal tumor cells by the EMT program $[12,13]$. BLBCs may originate from luminal progenitors and contain a number of distinct cell types including cells that express luminal, basal, and mesenchymal biomarkers [14-19]. More than half of BLBCs are associated with functional loss of BRCA1 caused by germline or somatic mutation, or promoter methylation $[9,20,21]$. We and others have demonstrated that depletion of Brca1 in mice activates EMT and induces highly heterogeneous BLBCs [18, 22, 23]. Most importantly, only a part of the cells in both human and mouse $B R C A 1$-deficient tumors exhibit mesenchymal features $[18,22-24]$, suggesting that a subset of BRCA1-deficient tumor cells have undergone EMT. Whether and how estrogen activates EMT in BRCA1-deficient, ER-negative basal-like tumor cells to promote their tumor initiation and progression remain elusive.

The phosphatidylinositol-3-kinase (PI3K)/AKT signaling pathway regulates cell proliferation, survival, metabolism, EMT, and stem cell fate [25-27], and is aberrantly activated in $77 \%$ of breast cancers [9], including BRCA1-deficient disease [28]. BRCA1 deficiency activates the PI3K/AKT pathway in immortalized fibroblasts and tumor cells by accumulating nuclear AKT [29]. Estrogen activates the PI3K/AKT pathway in both an ER-dependent and ER-independent manner [30, 31]. Estrogen also promotes the survival of Brca1-deficient tumor cells and mammary epithelial cells (MECs) [30]. Inhibition of the PI3K/AKT pathway reduces proliferation of Brca1-deficient mouse embryonic fibroblasts (MEFs) suppressing the growth of tumors generated by Brca1-deficient MEFs [28]. Whether estrogen promotes EMT and proliferation of ER-negative BRCA1deficient tumor cells through activation of the PI3K/ AKT pathway remains elusive.

The RB family of proteins (RB, p107, p130) that are phosphorylated and inactivated by CDK4 and CDK6 (CDK4/6), control the G1-to-S transition of the cell cycle. CDK4/6 are inhibited by inhibitors of CDK4/6 (INK4) including $\mathrm{p} 16^{\mathrm{INK} 4 \mathrm{~A}}(\mathrm{p} 16)$ and $\mathrm{p} 18^{\mathrm{INK} 4 \mathrm{C}}(\mathrm{p} 18)$ [32]. Inactivation of the INK4-CDK4/6-RB pathway is a common event in breast cancers $[9,32]$. p16 is inactivated in $\sim 30 \%$ of and p18 expression is frequently reduced in human breast cancers $[9,32] . \mathrm{RB}$ is a major target for genomic disruption in BRCA1 mutant human breast cancers, and most BRCA1-deficient BLBCs carry a dysfunctional INK4-CDK4/6-RB pathway [9, 33, 34]. All widely used $B R C A 1$ mutant breast cancer cell lines have deletions in either $R B$ or $p 16[35,36]$, reflecting the importance of inactivation of the INK4-CDK4/6-RB pathway in the proliferation of BRCA1-deficient tumor cells. We and others have reported that mice lacking $p 18$ or $R b$ and $p 107$ develop luminal-type mammary tumors [37, 38], suggesting a role of the RB pathway in controlling luminal tumorigenesis. BRCA1 deficiency in human and mouse MECs activates INK4-CDK4/6-RB pathway, inducing premature senescence $[19,39,40]$. We demonstrated that deletion of either $p 16$ or $p 18$ in mice rescues the premature senescence of MECs caused by Brcal deficiency, and that p16;Brcal and p18;Brca1 double-mutant mice develop BLBCs with EMT features $[19,23,39]$. These mutant mice provide unique mouse models to study the role of Brcal in the suppression of EMT and basal-like mammary tumorigenesis.

In this report, we used p16;Brca1 and p18;Brcal double-mutant mammary tumors and human BRCA1 mutant breast cancer patient-derived xenografts (PDX) to determine the function and mechanism of estrogen in promoting ER-negative BRCA1-deficient tumor initiation and progression. We demonstrate that estrogen promotes BRCA1-deficient tumor initiation and progression by stimulation of cell proliferation and activation of EMT, which are dependent on AKT activation, but independent of ER.

\section{Methods}

Mice, histopathologic analysis, and immunostaining

The generation of $p 18^{-/-}, p 18^{-/-} ; \mathrm{Brcal}^{M G K O}\left(\mathrm{p} 18^{-/-}\right.$;

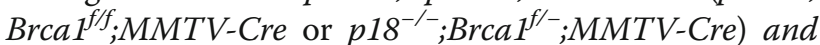
p16 $^{-/-} ;$Brcal $^{\text {MGKO }}\left(\right.$ p16 $^{-/-} ;$Brcal ${ }^{f / f} ; M M T V-C r e$ or $p 16^{-/-}$; Brcal $\left.{ }^{f /-} ; M M T V-C r e\right)$ mice has been described previously [23, 37, 39]. The Institutional Animal Care and Use Committee at the University of Miami approved all animal procedures. Histopathologic analysis and immunohistochemical analysis (IHC) were performed as described previously $[19,23,37]$. The primary antibodies used were Ck14 (Thermal Scientific), ER $\alpha$ (Santa Cruz), p-Akt (Ser473), p-4E-bp1 (Thr37/46), vimentin (Vim), E-cadherin (E-cad), p-Fra1 (Ser265) (Cell Signaling), Ki67 and fibronectin (Fn) (Abcam). Immunocomplexes were detected using the Vectastain $\mathrm{ABC} D \mathrm{DAB}$ kit according to the manufacturer's instructions (Vector Laboratories) or by using Alexa Fluor 488-conjugated or Alexa Fluor 594-conjugated secondary antibodies (Biolegend). The positive results of IHC were quantified by the $\mathrm{H}$ score, as previously described [41]. 


\section{Mammary and tumor cell preparation, fluorescence- activated cell sorting (FACS) analysis, cell sorting, and tumorsphere formation assay}

Mammary glands and tumors were dissected from female mice and cell suspensions were prepared as previously described [19, 23, 37]. For surface marker analysis; mammary and tumor cells were isolated, stained, and analyzed as previously described [23, 37]. Briefly, cells were stained with anti-CD24-PE (BD Pharmingen), anti-CD29-FITC (Biolegend, San Diego, CA, USA), biotinylated and allophycocyanin (APC)-conjugated CD45, CD31 and TER119 antibodies (BD Pharmingen), and Violet dye (Dead Cell Stain, ThermoFisher Scientific). For intracellular staining of Vim, $1 \times 10^{6}$ cells were fixed with $4 \%$ paraformaldehyde and permeabilized with $90 \%$ methanol. Anti-Vim was added as primary antibody and Alexa Fluor 594 anti-rabbit (Invitrogen) as secondary antibody. For intracellular staining of $E R \alpha$, cells were fixed and permeabilized with the Cytofix/Cytoperm fixation/ permeabilization kit (BD Pharmingen). ER $\alpha$ staining was performed according to the manufacturer's instructions. For bromodeoxyuridine (BrdU) incorporation, tumor cells were labeled with $10 \mu \mathrm{M}$ BrdU (Sigma) for $1.5 \mathrm{~h}$, fixed with $75 \%$ ethanol, and permeabilized with $2 \mathrm{M} \mathrm{HCl}$. The cells were then stained with fluorescein isothiocyanate (FITC)-conjugated anti-BrdU (Cell Signaling) and propidium iodide (PI) and analyzed by flow cytometry. FACS was performed using the LSR-Fortessa machine (BD Pharmingen). Data analysis was performed using Kaluza software (Beckman Coulter). To isolate tumor cells depleted of hematopoietic and endothelial cells, we stained mammary tumor cells with biotinylated and APC-conjugated CD45, CD31 and TER119 antibodies and Violet dye. Lin $^{-}$ $\left(\mathrm{CD} 45^{-}, \mathrm{CD} 31^{-}\right.$, TER119 $\left.{ }^{-}\right)$living (Violet dye negative) cells were sorted on a BD FACS SORP Aria-IIu machine. For tumorsphere formation assay, 30,000 $\mathrm{pl}^{-/-}$; $B r c a 1^{M G K O}$ mammary tumor cells were plated in triplicate ultra-low attachment plates with or without addition of $17 \beta$-estradiol (E2, Sigma) in serum-free DMEM-F12 supplemented with B27, epidermal growth factor (EGF), and basic fibroblast growth factor (bFGF) as described [23, 37]. The number and size of tumorspheres formed were calculated after 7 days.

\section{Cell culture, treatment, cell viability assay and western blot analysis}

MCF7 and SUM149 cells were cultured per American Type Culture Collection (ATCC) recommendations. Primary murine mammary tumor cells were cultured in phenol-free DMEM/F12 (Gibco), with 10\% charcoal-stripped FBS (Gibco), $10 \mu \mathrm{g} / \mathrm{ml}$ insulin, and $10 \mathrm{ng} / \mathrm{ml}$ EGF. For treatment of estrogen, AZD5363, and 4OHT, tumor cells were cultured in 10\% charcoal-stripped FBS in the presence of E2, AZD5363 (ApexBio Technology), 4OHT (Sigma), or dimethyl sulfoxide (DMSO) for the indicated times and then collected for further analysis. To determine cell viability, 50,000 cells were plated in 24-well plates and treated with DMSO or drugs at the indicated concentrations for 5 days. Viable cell numbers were determined on day 1, day 3 , and day 5 by an automatic cell counter (Bio-rad) with trypan blue exclusion. For western blot, tissue and cell lysates were prepared as previously reported [19, 23, 37]. Primary antibodies used are as follows: HSP90 (Santa Cruz), Gapdh (Ambion), ER $\alpha$ (Santa cruz), Brcal, p-Akt (Ser473), p-4E-bp1 (Thr37/46), p-mTor (Ser2248), p-Gsk3ß (Ser9), E-cad, Vim, Snail, Slug, p-Fra1 (Ser 265), p-Rb (ser780) (Cell Signaling) and Fn (Abcam).

\section{Transplantation, analysis of metastasis, and tumor treatment}

For mammary tumor cell transplantation, cells were suspended in a 50\% solution of Matrigel (BD) and then inoculated into the left and/or right inguinal mammary fat pads (MFPs) of 6-8-week-old female NSG mice (Jackson Laboratory) respectively. At 6 or 7 weeks after transplantation, animals were euthanized and mammary tumors were dissected for histopathological, immunohistochemical, and biochemical analyses. For PDX tumor tissue transplantation, $4 \mathrm{~mm} \times 2 \mathrm{~mm}$ tissue fragments prepared from BRCA1 mutant PDX tumors (TM00091, Jax lab) were transplanted into MFPs of 4-week-old female NSG mice. At 4 weeks after transplantation, or when tumor volume reached the maximal size that the Institutional Animal Care and Use Committee (IACUC) allowed, animals were euthanized and tumors were analyzed. For estrogen treatment in vivo, $0.72 \mathrm{mg}$ E2 (SE-121, IRA, Sarasota, FL, USA) or placebo beeswax pellet was implanted subcutaneously in mice receiving tumor cell or tissue transplants. To analyze the estrogen-induced metastasis from mammary tumors, metastatic $\mathrm{p}^{18^{-1-}} ; \mathrm{Brca1}^{\mathrm{MGKO}}$ tumor cells were inoculated into the MFPs of 4-week-old female NSG mice in which either E2 or placebo beeswax pellet was implanted subcutaneously. When newly generated tumors reached the maximum size $\left(1.3 \mathrm{~cm}^{3}\right)$ allowed by the IACUC in 3-6 weeks, or the mice became moribund, the lungs and other major organs were examined for detection of metastasis. For quantification of the number of metastatic nodules in the lungs, fixed lung tissues of all five lobes were sagittally sectioned at $200-\mu \mathrm{m}$ intervals. At least three sections for each lobe were prepared and stained with H.E. The metastatic nodules in each lobe of lung tissue were confirmed by H.E. staining, counted under a microscope, and averaged. The number of nodules in all lobes was then calculated. For AZD5363 treatment of pre-existing mammary tumors, $p 18^{-/-} ;$Brcal $^{\mathrm{MGKO}}$ tumor cells were transplanted into MFPs of NSG mice and allowed to reach $\sim 250 \mathrm{~mm}^{3}$ 
in size. Mice were then treated with AZD5363 $((150 \mathrm{mg} / \mathrm{kg}$ solubilized in a $10 \%$ DMSO $25 \% \mathrm{w} / \mathrm{v}$ (2-Hydroxypropyl)- $\beta$-cyclodextrin buffer (Sigma)) or vehicle by oral gavage once a day. The tumor size was measured daily with a caliper. Tumor volumes were calculated as:

$$
\mathrm{V}=\mathrm{a} \times \mathrm{b}^{2} / 2
$$

where "a" is the largest diameter and "b" is the smallest. Statistical significance was evaluated using the two-tailed $t$ test.

\section{Statistical analysis}

All data are presented as the mean \pm SD for at least three repeated individual experiments for each group. Quantitative results were analyzed by the two tailed Fisher exact test or two-tailed Student's $t$ test. $P<0.05$ was considered statistically significant.

\section{Results}

Deletion of Brca1 in p16 and p18 null epithelia results in ER-negative mammary tumors

We previously discovered that the expression of p16 and p18 along with senescence markers was increased in MECs of $\mathrm{Brcal}^{+/-}$(heterozygous germline deletion of Brca1) and Brca1 ${ }^{M G K O}$ (specific deletion of Brca1 in epithelia) mice $[19,23,39] . p 18^{-/-}$mice in the Balb/c background developed ER-positive luminal-type mammary tumors [37] whereas $p 18^{-/-} ; \mathrm{Brcal}^{+/-}$double mutant mice formed ER-negative basal-like mammary tumors [19]. We generated $p 16^{-/-} ; \mathrm{Brcal}^{\mathrm{MGKO}}$ and $p 18^{-/-} ; \mathrm{Brcal}^{\mathrm{MGKO}}$ double-mutant mice in the Balb/c-B6 mixed background. We found that $47 \%$ of $p 18^{-/-}, 73 \%$ of $p 18^{-/-} ;$Brcal $^{M G K O}$, $60 \%$ of $p 16^{-1-} ; B r c a 1^{M G K O}$, and $8 \%$ of $B r c a 1^{M G K O}$ mice in the Balb/c-B6 mixed background developed mammary tumors, yet no $p 16^{-1-}$ mice developed mammary tumors at similar ages (Table 1 and Additional file 1: Figure S1). Though the mammary tumor incidence of $p 18^{-/-}$mice in the Balb/c-B6 mixed background was lower than those in the Balb/c background (47\% vs. 83\%) (Table 1 and Reference $[19,37]), p 18^{-/-}$tumors in the Balb/c-B6 mixed background were also predominantly ER $\alpha$-positive, Ck5/ CK14 negative tumors (Table 1 and Additional file 1: Figure S1). These results indicate that loss of p18 induces ER-positive mammary tumors independent of mouse genetic background. Further analysis revealed that only $18 \%(n=11)$ of $p 18^{-/-} ; B r c a 1^{M G K O}$ and none $(n=6)$ of $\mathrm{p}^{-6^{-/-}} ; \mathrm{Brcal}^{\mathrm{MGKO}}$ tumors were positive for ER $\alpha$. These rates were significantly lower than that of $p 18^{-/-}$tumors $(71 \%, n=7)$. Consistent with these results, $82 \%$ of $p 18^{-1-} ;$ Brcal $^{M G K O}$ and all of $p 16^{-1-} ;$ Brcal $^{M G K O}$ tumors were positive for $\mathrm{Ck} 5$ or $\mathrm{Ck} 14$, whereas only $29 \%$ of $p 18^{-/-}$tumors were positive for $\mathrm{Ck} 5$ or $\mathrm{Ck} 14$ (Table 1 and Additional file 1: Figure S1). These data confirm the role of Brcal in the suppression of ER-negative, basal-like tumorigenesis in an epithelium autonomous manner.

\section{Deletion of Brca1 stimulates the tumor-initiating potential of the tumor cells}

We transplanted $10^{6}$ primary tumor cells from three individual $p 16^{-1-} ;$ Brcal $^{M G K O}$ and four $p 18^{-/-} ;$Brcal $^{M G K O}$ tumors into MFPs of NSG mice respectively and found that all of these cells efficiently generated tumors in 67 weeks. Furthermore, we found that as few as 4000 $p 16^{-/-} ;$Brcal $^{M G K O}$ or $p 18^{-/-} ;$Brcal $^{M G K O}$ tumor cells efficiently generated tumors in the same period (Table 2 and data not shown). In contrast, as many as $10^{7}$ tumor cells from three individual $p 18^{-/-}$tumors did not generate tumors in 6-7 weeks when transplanted (experiment 1 in Table 2 and data not shown). Since $p 16^{-1-}$ mice did not develop mammary tumors, we were unable to determine the tumor initiating potential of $p 16^{-1-}$ mammary tumor cells by transplantation assay. These results suggest that the deletion of Brcal enhances the tumor-initiating potential of tumor cells, which is consistent with our previous finding that loss of Brcal activates EMT and induces ER-negative basal-like mammary tumors with enriched CSCs [23].

Table 1 Deletion of Brca1 in p18 and p16 null epithelia induces estrogen receptor (ER)-negative mammary tumors

\begin{tabular}{|c|c|c|c|c|c|}
\hline Genotype $^{a}$ & Mammary tumor number & ERa + tumor number & $\%$ ERa + cells/tumor & Ck5/Ck14+ tumor number & $\%$ Ck5/Ck14+ cells/tumor \\
\hline Wild-type & $0 / 9$ & & & & \\
\hline$p 18^{-/-}$ & 7/15 (47\%) & $5 / 7(71 \%)$ & $2 \%-50 \%$ & 2/7 (29\%) & $2 \%, 5 \%$ \\
\hline Brcal MGKO b & $1 / 13(8 \%)$ & $0 / 1$ & & $1 / 1(100 \%)^{c}$ & $20 \%$ \\
\hline $\mathrm{p} 8^{-/-} ; \mathrm{BrCa}^{\mathrm{MGKO}}$ & $11 / 15(73 \%)$ & $2 / 11(18 \%)^{d}$ & $2 \%, 5 \%$ & $10 / 11(82 \%)^{d}$ & $2-80 \%$ \\
\hline$p 16^{-1-}$ & $0 / 20$ & & & & \\
\hline $\mathrm{p} 16^{-1-} ; \mathrm{BrCa}^{\mathrm{MGKO}}$ & $6 / 10(60 \%)$ & $0 / 6^{e}$ & & $6 / 6(100 \%)^{e}$ & $2 \%-80 \%$ \\
\hline
\end{tabular}

${ }^{a}$ All mice were in the Balb/c-B6 mixed background and were at the age of 12-26 months

${ }^{\mathrm{b}} \mathrm{BrCa}^{\mathrm{MGKO}}{ }^{\text {Brcal }}{ }^{\mathrm{f} / \mathrm{f}}$;MMTV-Cre or BrCa1 ${ }^{\mathrm{f} /-}$;MMTV-Cre

${ }^{\mathrm{C}}$ A mouse with tumor harboring p53 mutation was 24 months of age

${ }^{\mathrm{d}}$ Significance for $p 18^{-/-} ; \mathrm{Brca}^{\mathrm{MGKO}}$ and $p 18^{-1-}$ tumors analyzed by the two-tailed Fisher's exact test

${ }^{\text {e}}$ Significance for $p 16^{-/-} ; B r c a 1^{M G K O}$ and $p 18^{-/-}$tumors analyzed by the two-tailed Fisher's exact test 
Table 2 Brcal deficiency promotes mammary tumor initiation

\begin{tabular}{|c|c|c|c|}
\hline Genotype & p18 $\%$-Donor A & & p18 $; 8^{-1}$ Brca ${ }^{M G K O}$ - Donor \\
\hline Number of tumor cell transplanted ${ }^{a}$ & $1 \times 10^{7} /$ mouse & & $1 \times 10^{6} /$ mouse \\
\hline Experiment number & 1 & 2 & 1 \\
\hline Tumor incidence ${ }^{\mathrm{b}}$ (7 weeks) & $0 / 6$ & $3 / 6(50 \%)^{c}$ & $4 / 4(100 \%)$ \\
\hline Genotype & p18 $8^{-/-D o n o r ~ B ~}$ & & p16 ${ }^{-1} ;$ Brcal $^{\text {MGKO }}$ - Donor \\
\hline Number of tumor cell transplanted ${ }^{a}$ & $3 \times 10^{6} /$ mouse & & $1 \times 10^{6} /$ mouse \\
\hline Experiment number & 1 & 2 & 1 \\
\hline Tumor incidence (6 weeks) & $0 / 6$ & $1 / 4(25 \%)^{c}$ & $4 / 4(100 \%)$ \\
\hline
\end{tabular}

ansorted primary tumor cells were used

${ }^{\mathrm{b}}$ Tumors generated larger than $12 \mathrm{~mm}^{3}$ in size were counted

'Tumor cells were transplanted into MFPs of NSG mice with E2 supplement. A statistical significance from E2-treated and non-E2 treated groups combining both p $18^{-/-}$-Donor $A$ and $-B$ transplants by two tailed Fisher Exact test

\section{Generation of transplantable ER-negative Brca1-deficient mammary tumor models}

In mammary and tumor cells ER $\alpha$ expression is restricted to the $\mathrm{CD} 24^{+} \mathrm{CD} 29^{\text {low }}$ luminal population while the $\mathrm{CD} 24^{+} \mathrm{CD} 29^{\text {high }}$ population is ER $\alpha$ negative while also enriched with basal and stem cells [42, 43]. Consistently, we previously reported that $40-60 \%$ of the cells in most of the ER-positive $p 18^{-/-}$tumors and less than $10 \%$ of the cells in most of the ER-negative $p 18^{-/-} ;$Brcal $^{M G K O}$ tumors were $\mathrm{CD} 24^{+} \mathrm{CD} 29^{\text {low }}[23,37]$. We detected a predominant $\mathrm{CD} 24^{+} \mathrm{CD} 29^{\text {high }}$ population containing $60-81 \%$ of the cells in most of the $p 18^{-/-} ;$Brcal $^{M G K O}$ and $p 16^{-/-} ;$Brcal $^{M G K O}$ tumors (Additional file 2: Figure S2A) [23]. We chose and further characterized two individual $p 18^{-/-} ;$Brcal $^{M G K O}$ tumors in addition to two individual $p 16^{-/-} ; B r c a 1^{M G K O}$ tumors in which $\mathrm{ER} \alpha$ was undetectable by western blot and IHC (Table 1, Additional file 1: Figure S1, and Fig. 3c); there were more than $75 \% \mathrm{CD} 24^{+} \mathrm{CD} 29^{\text {high }}$ cells and less than $2 \% \mathrm{CD} 24^{+} \mathrm{CD} 29^{\text {low }}$ cells (Additional file 2: Figure S2A and data not shown). Taking advantage of the tumors predominantly composed of $\mathrm{CD} 24^{+} \mathrm{CD} 29^{\text {high }}$ cells, we transplanted $6 \times 10^{4}$ FACS-sorted Lin $^{-}$cells (depleted of hematopoietic and endothelial cells) from a $p 18^{-1}$ ${ }^{-}$;Brca $1^{M G K O}$ tumor and a $p 16^{-1-} ;$ Brcal $^{M G K O}$ tumor into eight MFPs of NSG mice (four for each cell type). After 1-2 months all recipient mice produced mammary tumors that were ER $\alpha$ negative (placebo group in Table 3, Additional file 2: Figure S2B, C, and data not shown). We cultured these tumor cells and found that most (>90\%) of the cells maintained their $\mathrm{CD} 24^{+} \mathrm{CD} 29^{\text {high }}$ feature and less than $2 \%$ of the cells were $\mathrm{CD} 24^{+} \mathrm{CD} 29^{\text {low }}$, whereas, as a control, about half of the $p 18^{-/-}$tumor cells were $\mathrm{CD} 24^{+} \mathrm{CD} 29^{\text {low }}$ (Additional file 2: Figure S2D). We determined expression of ER $\alpha$ by FACS and found that all cells derived from four individual $p 18^{-/-} ; B r c a 1^{M G K O}$ and $p 16^{-/-} ; \mathrm{Brcal}^{M G K O}$ tumors were ER $\alpha$ negative whereas, as controls, $59 \%$ of
MCF7 and $43 \%$ of $p 18^{-/-}$tumor cells were ER $\alpha$ positive, respectively (Additional file 2: Figure S2E). We transplanted $1 \times 10^{6}$ cultured cells from each of the two individual $\mathrm{pl}^{-1-} ; \mathrm{Brcal}^{\mathrm{MGKO}}$ and $\mathrm{pl6}^{-/-} ; \mathrm{Brcal}^{\mathrm{MGKO}}$ tumors into MFPs of NSG mice. We found all recipient mice also generated ER $\alpha$-negative mammary tumors, which were indistinguishable from tumors generated by $\mathrm{Lin}^{-}$primary tumor cells in respect to ER $\alpha$ negativity (placebo group in Table 3, Additional file 2: Figure S2F, G, and data not shown). In summary these results demonstrate that transplantation of representative $p 18^{-/-} ; \mathrm{Brcal}^{\mathrm{MGKO}}$ and $p 16^{-1-}$;Brcal ${ }^{M G K O}$ tumor cells into MFPs of NSG mice generate reproducible ER-negative tumors, which build a model system to study BRCA1-deficient mammary tumor development and progression.

Table 3 Estrogen promotes Brca1-deficient mammary tumor initiation and progression

\begin{tabular}{|c|c|c|}
\hline Genotype & \multicolumn{2}{|c|}{ p18 ${ }^{-1} ;$ Brcal $^{\text {MGKO }}$ - Donor A } \\
\hline number of tumor cell transplanted ${ }^{a}$ & \multicolumn{2}{|c|}{$1 \times 10^{6} /$ mouse } \\
\hline Treatment & Placebo & E2 \\
\hline Tumor incidence (7 weeks) & $4 / 4(100 \%)$ & $4 / 4(100 \%)$ \\
\hline Tumor size $\left(\mathrm{mm}^{3}\right)$ & $426 \pm 98$ & $1294 \pm 265^{c}$ \\
\hline Tumor number with metastasis & $0 / 4$ & $1 / 4^{d}$ \\
\hline Genotype & \multicolumn{2}{|c|}{ p16 $6^{-/} ;$Brcal $^{\text {MGKO }}$ - Donor B } \\
\hline number of tumor cell transplanted ${ }^{b}$ & \multicolumn{2}{|c|}{$6 \times 10^{4} /$ mouse } \\
\hline T reatment & Placebo & E2 \\
\hline Tumor incidence ( 6 weeks) & $4 / 4(100 \%)$ & $4 / 4(100 \%)$ \\
\hline Tumor size $\left(\mathrm{mm}^{3}\right)$ & $50 \pm 22$ & $785 \pm 452^{c}$ \\
\hline
\end{tabular}

${ }^{a}$ Cultured tumor cells were used

${ }^{\mathrm{b}}$ FACS-sorted Lin- tumor cells were used

${ }^{\mathrm{C}} \mathrm{A}$ statistical significance from E2-and Placebo-treated groups by two tailed $\mathrm{t}$ test

${ }^{\mathrm{d}} \mathrm{A}$ tumor metastasized to the lung and liver. No statistical significance was detected in tumor metastasis between E2- and placebo-treated groups by two tailed Fisher Exact test 


\section{Estrogen promotes Brca1-deficient mammary tumor initiation and metastasis}

To determine the role of estrogen in Brca1-deficient mammary tumorigenesis, we transplanted Brca1-proficient and Brca1-deficient mammary tumor cells into MFPs of NSG mice with or without estrogen (17 $\beta$-estradiol, E2) supplement. We found with E2 supplement, a half ( 3 out of 6 ) and a quarter ( 1 out of 4 ) of the mice that received two individual $p 18^{-/-}$tumor cell transplants yielded small tumors, respectively (experiment 2 in Table 2 and Additional file 3: Figure S3). Importantly, all $p 18^{-/-} ;$Brca $^{M G K O}$ and $p 16^{-/-} ;$Brca $^{M G K O}$ tumor cells yielded significantly larger tumors in NSG mice when transplanted with E2 supplement compared with those with placebo treatment (Table 3). IHC and western blot analysis confirmed the expression of Brca1 and ER $\alpha$ in regenerated mammary tumors by $p 18^{-/-}$tumor cells and lack of Brcal and ER $\alpha$ in regenerated tumors by $p 18^{-/}$ ${ }^{-}$;Brca1 ${ }^{M G K O}$ cells with E2 supplement (Additional file 3: Figure S3 and Additional file 4: Figure S4B, C). Pathologic analysis revealed that relative to placebo-treated tumors, E2-treated $p 18^{-/-} ; B r c a 1^{M G K O}$ and $p 16^{-/-}$; $B r c a 1^{M G K O}$ tumors were poorly differentiated, more aggressive (increased necrosis, squamous metaplasia, spindle cells, nuclear-cytoplasm ratio, and mitotic indices) and contained highly heterogeneous cell types, whereas, E2-treated $p 18^{-/-}$tumors retained well-differentiated glandular structures (Fig. 1a and Additional file 3: Figure S3). Notably, one out of four $p 18^{-/-} ; B r c a 1^{M G K O}$ tumors that were treated with E2 metastasized to the lungs and liver (Table 3 and Fig. 1a). We found that 51\% (25/49) of DMSO-treated tumorspheres were smaller than $50 \mu \mathrm{m}$ whereas $63 \%(47 / 74)$ of E2-treated tumorspheres were larger than $50 \mu \mathrm{m}$. The number of E2-treated tumorspheres that were larger than $100 \mu \mathrm{m}$ or that were 50$100 \mu \mathrm{m}$ was significantly more than that of DMSO-treated tumorspheres. Notably, the increased number of $p 18^{-/-} ;$Brcal $^{M G K O}$ tumorspheres was not inhibited by $4 \mathrm{OHT}$, an ER antagonist (Fig. 1b). These data suggest that E2 stimulates Brca1-deficient CSCs independent of ER. Together, these results demonstrate that in addition to the increased tumor-initiating potential of ER-positive Brca1-proficient tumor cells, estrogen enhances the number of Brca1-deficient CSCs and promotes ER-negative basal-like tumor initiation and progression.

Consistent with the findings derived from E2-treated

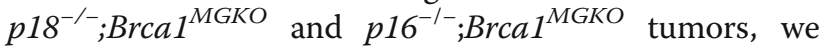
also found that BRCA1 mutant PDX tumor development was significantly enhanced by $\mathrm{E} 2$ treatment relative to that by placebo (Fig. 1c). E2-treated BRCA1 mutant PDX tumors were also less differentiated, but more heterogeneous and invasive than placebo-treated tumors (Fig. 1d). These data further support the finding that estrogen promotes human BRCA1-deficient tumor initiation and progression.

To further investigate the role of estrogen in Brca1-deficient mammary tumor progression, we isolated a highly metastatic $p 18^{-/-} ; B r c a 1^{\text {MGKO }}$ tumor cell line from a mammary tumor (tumor B) that was metastasized to lung. We then transplanted metastatic p18 $18^{-1-}$ Brca1 $1^{\mathrm{MGKO}}$ tumor cells into the MFPs of NSG mice with the supplement of either E2 or placebo pellet. We found that all newly generated mammary tumors metastasized to lung in 3-6 weeks. Notably, E2-treated mice with mammary tumors developed significantly more metastatic nodules in their lungs when compared with placebo-treated animals $(115 \pm 62$ vs $241 \pm 75$, $p<0.05$ ) (Fig. 2a-c, and Additional file 5: Figure S5). IHC analysis revealed that metastasized tumors in lung were negative for ER (Fig. 2d). These results confirm that estrogen promotes ER-negative Brca1-deficient mammary tumor metastasis.

\section{Estrogen activates EMT in a subset of Brca1-deficient tumor cells}

Estrogen has been found to activate EMT and stimulate the function of ER-negative breast CSCs through paracrine signaling produced in ER-positive cells in response to estrogen $[7,8]$. However, clinically hormone therapy prevents development and suppresses the progression of BRCA1-deficient, ER-negative breast cancers [3, 4]. Inspired by the finding that a fraction of BRCA1-deficient human and mouse tumor cells harbor EMT features [16$19,22-24,39,44]$, and the finding that E2 enhanced the heterogeneity of $p 18^{-/-} ; B r c a 1^{M G K O}$ and $p 16^{-/-} ; B_{r c a 1} 1^{M G K O}$ tumors with elevated squamous metaplasia and spindle-shaped cells (typical morphological characteristics of mesenchymal cells), we hypothesized that estrogen promotes EMT and stimulates BRCA1-deficient, ER-negative tumorigenesis independent of ER. We found by western blot analysis that E2-treated $p 18^{-/-} ; B_{r c a 1}{ }^{M G K O}$ tumors expressed a higher level of EMT marker (Vim) and EMT-inducing transcription factors (EMT-TFs) including p-Fra1 and Snail, than placebo-treated tumors. Importantly, we noticed by IHC that the number of cells that are positive for EMT markers and EMT-TFs was drastically enhanced in E2-treated $p 18^{-/-} ; B r c a 1^{M G K O}$ tumors than in placebo-treated counterparts (Fig. 3a and Additional file 4: Figure S4A). We confirmed, as expected, that metastasized mammary tumors in lung were positive for Vim and p-Fra1 (Fig. 2d). These data suggest that estrogen activates EMT in a subset of ER-negative Brca1-deficient epithelial tumor (carcinoma) cells that have not undergone EMT, leading to an increase in the fraction of mesenchymal-like cells in Brca1-deficient tumors.

We examined BRCA1 mutant PDX tumors and discovered that more than $80 \%$ of tumor cells expressed a 


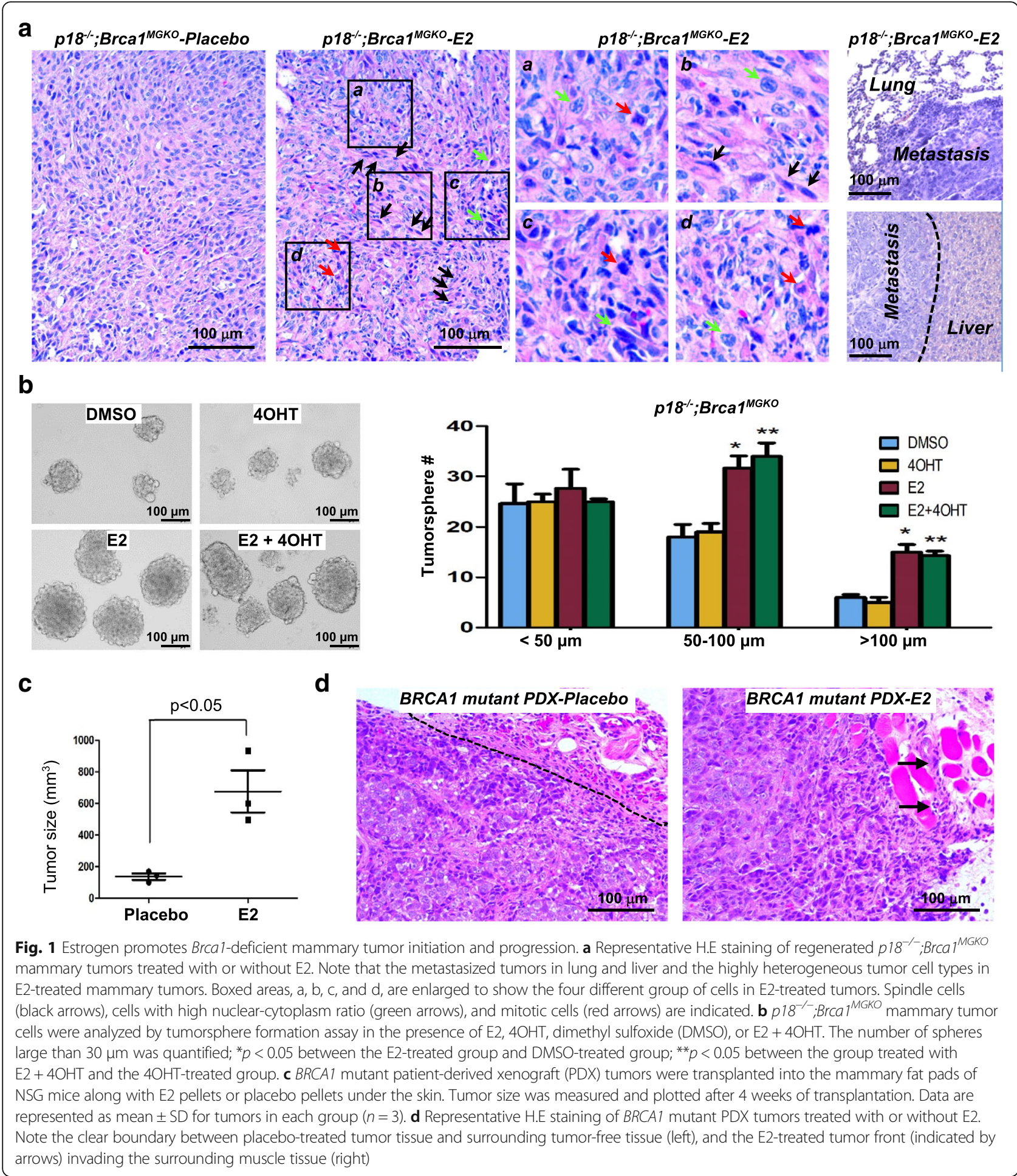

high level of VIM without treatment (Fig. 3b). These data are supported by the findings in both mouse [23] and human mammary tumors $[24,44]$ that most BRCA1 mutant tumors are VIM positive and some of them are predominantly composed of VIM-positive cells. Though we failed to detect a further increase in the number of
VIM-positive cells by E2-treatment in BRCA1 mutant PDX tumors (Fig. 3b), the number of tumor cells that are positive for fibronectin, another key marker of mesenchymal cells, and for SNAIL and SLUG was drastically enhanced by E2 relative to the placebo (Fig. 3b). These results indicate that estrogen also 


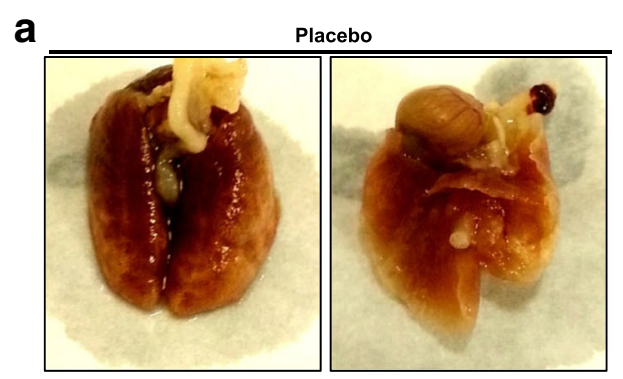

b
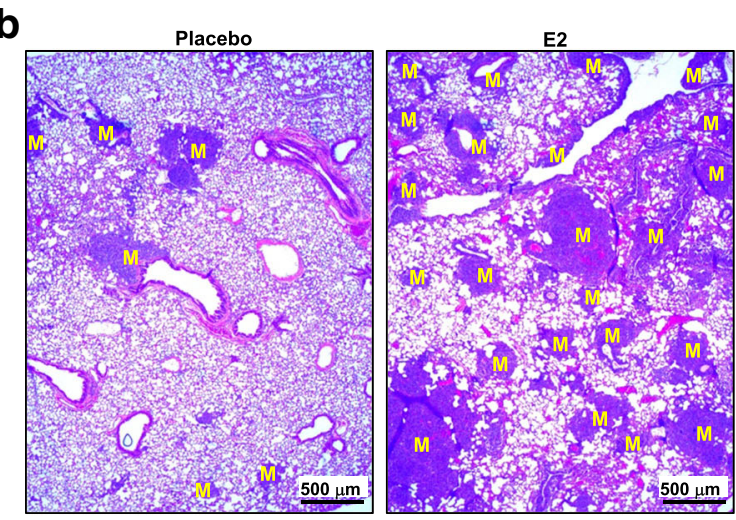

d
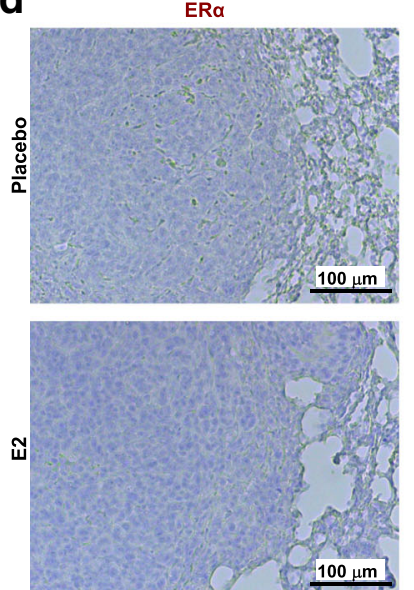
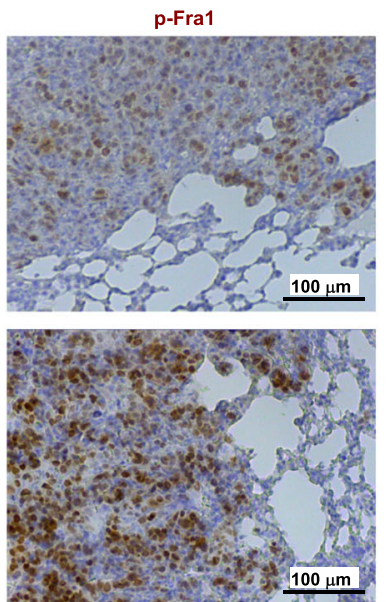

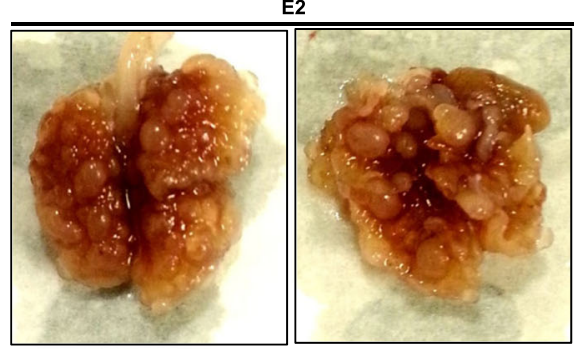

C
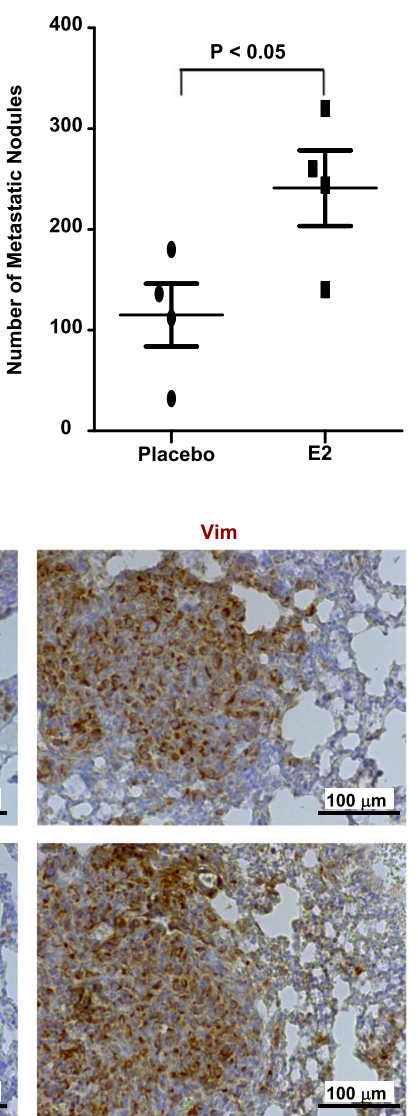

Fig. 2 Estrogen promotes Brcal-deficient mammary tumor metastasis. a-d We inoculated $1 \times 10^{6}$ metastatic $p 18^{-/-} ;$Brca ${ }^{M G K O}$ tumor (donor B) cells into the mammary fat pads of 4-week-old female NSG mice in which either E2 or placebo Beeswax pellet was implanted subcutaneously. When newly generated tumors reached maximum size $\left(1.3 \mathrm{~cm}^{3}\right)$ allowed by the IACUC in 3-6 weeks, or the mice became moribund, lungs were examined for gross appearance (a), H.E. staining (b), and quantification of the number of metastatic nodules (c). M, metastatic nodules. Data in (c) are mean \pm SD for the numbers of metastatic nodules detected in all lobes of the lungs in each group $(n=4)$. $\mathbf{d}$ Representative immunohistochemical analysis of lung metastasis with antibodies against estrogen receptor (ER)a, p-fos-related antigen 1 (Fra1), and vimentin (Vim)

activates EMT in a subset of human BRCA1 mutant tumor cells.

As no tumor formed after the transplantation of $p 18^{-/-}$tumor cells without an E2 supplement (Table 2), we determined EMT markers in E2-treated tumors and primary tumors. We found no significant change in the expression of E-cad, p-Fra1, and Snail in E2-treated $p 18^{-/-}$tumors compared to $p 18^{-/-}$primary tumors (Fig. 3c, Additional file 4: Figure S4C, and data not shown). Notably, except for a slight increase in Slug in a longer treatment, the expression of E-cad, Vim, Snail, and p-Fra1 in $p 18^{-/-}$tumor cells in culture was not affected by E2 either, whereas, the expression of Vim, Snail, and Slug in $p 18^{-/-} ;$Brca $1^{M G K O}$ tumor cells was clearly enhanced by E2 under the same culture conditions (Fig. 3e, g and Additional file 6: Figure S6A-D). Together, these results indicate that estrogen promotes EMT in 


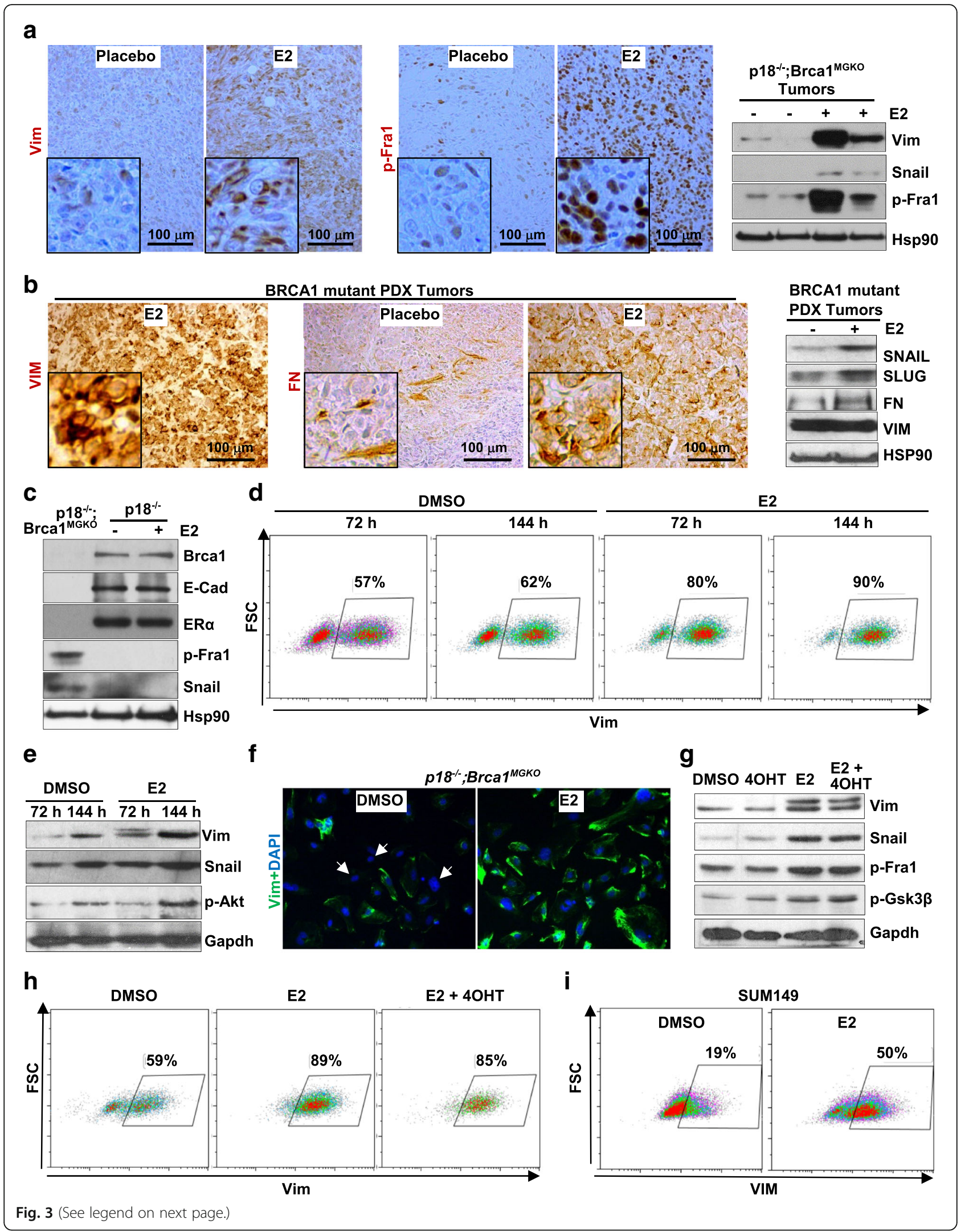




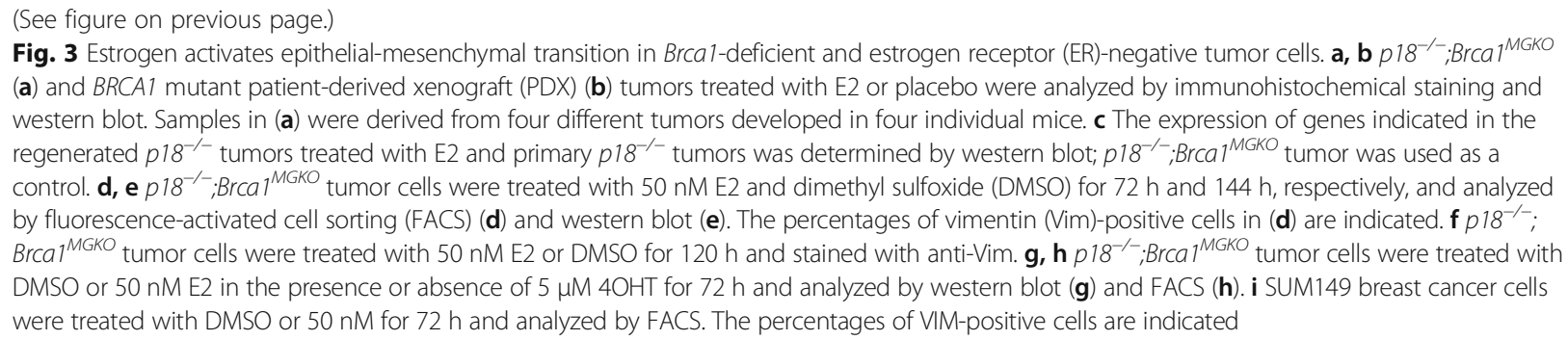

Brca1-deficient, but not in Brca1-proficient, tumor cells.

Because the number of cells with mesenchymal features varies in different $B R C A 1$-deficient tumors, we screened a panel of primary $p 18^{-/-} ; B r c a 1^{M G K O}$ tumor cells by FACS for expression of Vim and identified at

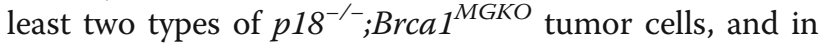
one of these, Vim-positive cells constituted $30-65 \%$ of the total tumor cells (type 1) and in the other, Vim-positive cells constituted $>90 \%$ of the total cells (type 2) (Fig. 3d-h and Additional file 6: Figure S6C). Due to the enrichment of EMT-promoting factors including transforming growth factors (TGFs) in serum, culture immortalized MECs in serum in vitro activates EMT [45]. Therefore, we cultured tumor cells in charcoal-stripped FBS with minimal hormones and cytokines (http://www.thermofisher.com) and performed all of our in vitro experiments using either primary or early passaged (before passage 3) tumor cells.

We treated $p 18^{-/-} ;$Brca1 ${ }^{M G K O}$ tumor cells with E2 in multiple time periods and observed by western blot that E2 stimulated expression of Vim and EMT-TFs including p-Fra1 and/or Snail/Slug in both type of cells (Fig. 3d-h, Additional file 6: Figure S6), indicating E2 promotes EMT in Brca1-deficient tumor cells in vitro. As the majority of BRCA1-deficient tumors contain a fraction of cells that are positive for VIM and/or other mesenchymal markers, and only a small number of human BRCA1-deficient tumors, i.e. metaplastic breast cancers, are predominantly composed of mesenchymal/ VIM-positive cells [16-19, 24, 39, 44, 46], we therefore focused on type $1 \mathrm{plo}^{-/-} ;$Brcal $^{M G K O}$ tumor cells. When type $1 \mathrm{p}^{-/ 8^{-}} ;$Brcal $^{\text {MGKO }}$ tumor cells were examined by immunofluorescent staining and FACS, we found that E2 treatment enhanced the number of Vim-positive cells - converting Vim-positive cells from $57-62 \%$ to $80-90 \%$ after $72 \mathrm{~h}$ (Fig. 3d, f, h). Furthermore, the increase in Vim expression and conversion of cells from Vim-negative to positive by E2 in $p 18^{-/-} ; \mathrm{Brcal}^{\mathrm{MGKO}}$ tumor cells was not blocked by $4 \mathrm{OHT}$ (Fig. 3g, h), whereas, 4OHT effectively blocked E2-enhanced cell proliferation and RB phosphorylation in ER-positive MCF7 cells, as expected (Additional file 7: Figure S7). These results demonstrated that estrogen activates EMT in a subset of Brca1-deficient tumor cells that have not undergone EMT, and further indicated that estrogen promotes EMT in ER-negative Brca1-deficient tumor cells independent of ER.

We then selected a BRCA1 mutant, ER-negative human breast cancer cell line, SUM149, in which p16 is deleted and VIM is expressed in $10-30 \%$ of total cells [35, 47-49]. This cell line shares many genetic ( $p 16 / p 18$ and Brcal loss-of-function mutation) and phenotypical (ER negative with a subset of cells exhibiting EMT features) similarities with p16;Brca1 and p18;Brca1 mutant murine mammary tumor cells. We found that E2 treatment also drastically enhanced the number of Vim-positive cells - from $19 \%$ to $50 \%$ after $72 \mathrm{~h}$ (Fig. 3i). Notably, it has been reported that in the SUM149 cell line, VIM-positive, stem/basal cells are able to efficiently generate both basal and luminal cells, whereas, VIM-negative, luminal cells rarely generate VIM-positive, stem/basal cells under serum-containing culture condition [47]. In addition, we also detected by western blot the increase in VIM, p-FRA1, and SNAIL in SUM149 cells in response to E2 treatment (Additional file 6: Figure S6E), indicating the activation of EMT by estrogen.

In summary, these in vitro results confirmed that estrogen activates EMT in a subset of Brca1-deficient tumor cells with epithelial features, which is independent of ER.

\section{Estrogen stimulates Brca1-deficient tumor cell proliferation}

We performed IHC of mammary tumors generated by primary tumor cells derived from three individual $p 16^{-/-}$; Brcal $1^{\text {MGKO }}$ and four $p 18^{-/-} ;$Brcal $^{\text {MGKO }}$ tumors. We found that all newly generated tumors contained $\mathrm{Ck} 5$ or $\mathrm{Ck} 14$ (Ck5/Ck14)-positive cells. We observed that the more Ck5/Ck14-positive cells in primary tumors, the more Ck5/Ck14-positive cells will be detected in the regenerated tumors, though the percentages of Ck5-positive or Ck14-positive cells varied among tumors (Figs. 4, 6 and data not shown) [19, 23, 39]. These results suggest that newly generated $p 16^{-1-} ; B r c a 1^{M G K O}$ and $p 18^{-/-}$; Brcal ${ }^{\text {MGKO }}$ mammary tumors maintain their basal-like tumor phenotype. We investigated cell proliferation in tumors by Ki67 staining and found that there were more Ki67-positive cells in E2-treated tumors than in 


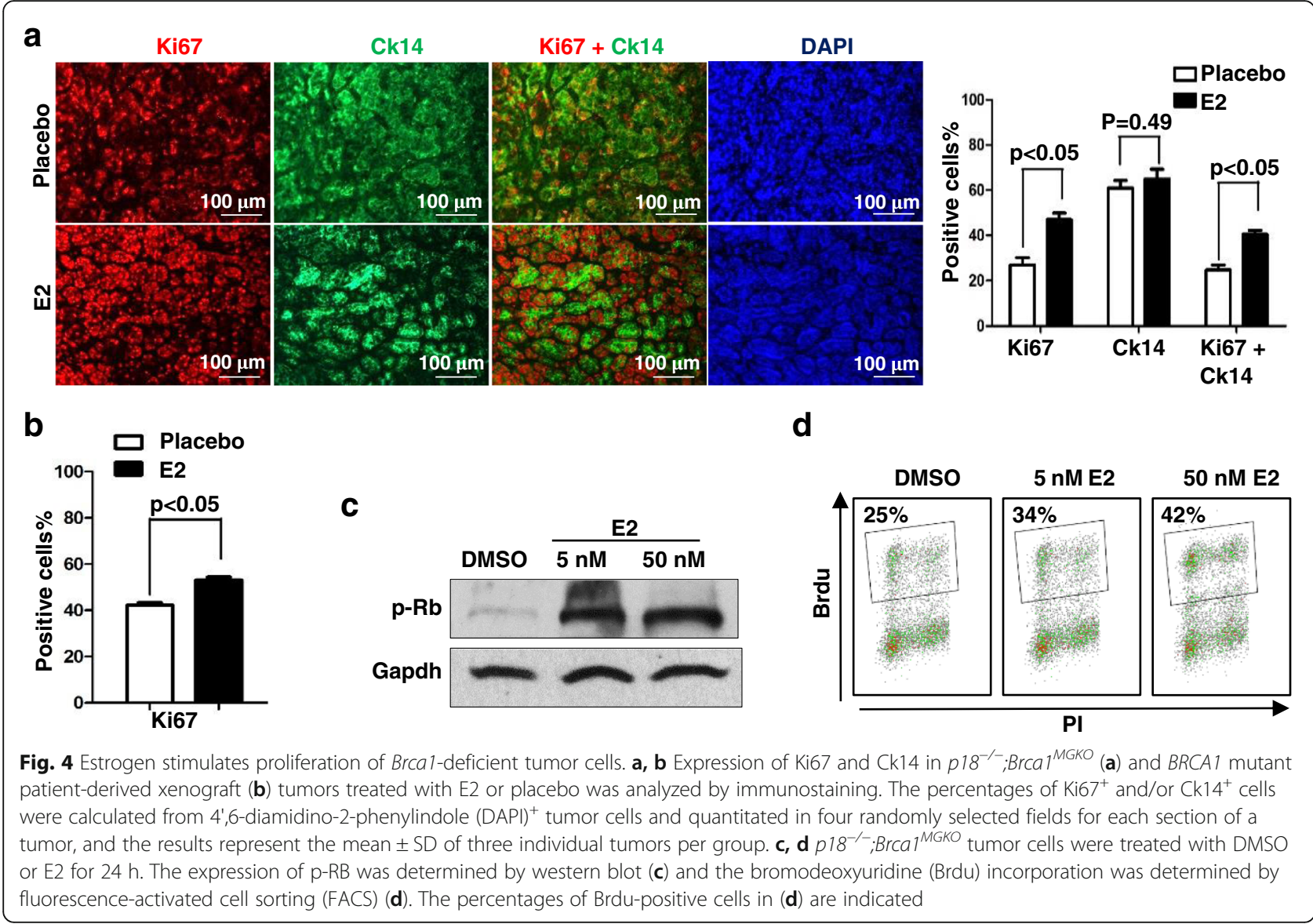

placebo-treated tumors. Furthermore, the majority of Ki67 positive cells in E2-treated tumors were also positive for CK14 (Fig. 4a). We then performed similar analysis for BRCA1 mutant PDX tumors and found that E2 treatment also enhanced the number of Ki67-positive cells in tumors, most of which are also CK14 positive (Fig. 4b, and data not shown). These results indicate that estrogen stimulates proliferation of Brca1-deficient basal-like tumor cells in vivo.

We cultured cells derived from three individual $p 18^{-/-}$; Brcal ${ }^{M G K O}$ tumors and found that E2 treatment in both type 1 and type 2 tumor cells enhanced the number of cells (Fig. 6b, Additional file 8: Figure S8C), promoted phosphorylation of RB (Fig. 4c), and stimulated incorporation of BrdU in cells (Fig. 4d). These data confirm the role of estrogen in stimulation of proliferation of Brca1deficient tumor cells.

\section{Estrogen activates the AKT pathway in BRCA1-deficient mammary tumors}

During the course of analysis of the role of estrogen in activating EMT, we observed that E2 stimulated expression of $\mathrm{p}$-Akt, $\mathrm{p}-\mathrm{Gsk} 3 \beta$, and $\mathrm{p}-4 \mathrm{Ebp} 1$, downstream targets of Akt, in $p 18^{-/-} ; B r c a 1^{M G K O}$ tumor cells, which was not blocked by $4 \mathrm{OHT}$ (Fig. 3e, g). We examined tumors by IHC and western blot analysis, and found that the expression of p-Akt and its targets, p-4Ebp1, p-mTor, and p-Gsk3 3 , was significantly enhanced in E2-treated tumors when compared with placebo-treated tumors. (Fig. 5a, b). We treated $p 18^{-/-} ; B r c a 1^{M G K O}$ and SUM149 tumor cells with or without E2 and found that E2 stimulated expression of p-Akt, p-4Ebp1, p-mTor, and $\mathrm{p}-$ Gsk3 $\beta$ in all time points tested from 2 to $144 \mathrm{~h}$ (Fig. 3e, g, Fig. 5c, Fig. 6a and Additional file 6: Figure S6A, B, E). Consistent with the data derived from $p 18^{-1-} ;$ Brca $^{M G K O}$ tumors, E2 treatment also significantly enhanced the expression of p-AKT, p-4EBP1, p-mTOR, and p-GSK3 $\beta$ in $B R C A 1$ mutant PDX tumors relative to placebo treatment (Fig. 5d, e and Additional file 8: Figure S8A, B). These results indicate that estrogen activates the AKT pathway in BRCA1-deficient mammary tumor cells independent of ER.

Inhibition of AKT suppresses EMT and cell proliferation preventing Brca1-deficient tumor progression

Along with activation of the Akt pathway, estrogen promoted EMT and proliferation in Brca1-deficient mammary tumor cells, which prompted us to test whether pharmaceutical inhibition of Akt activity has any effect 


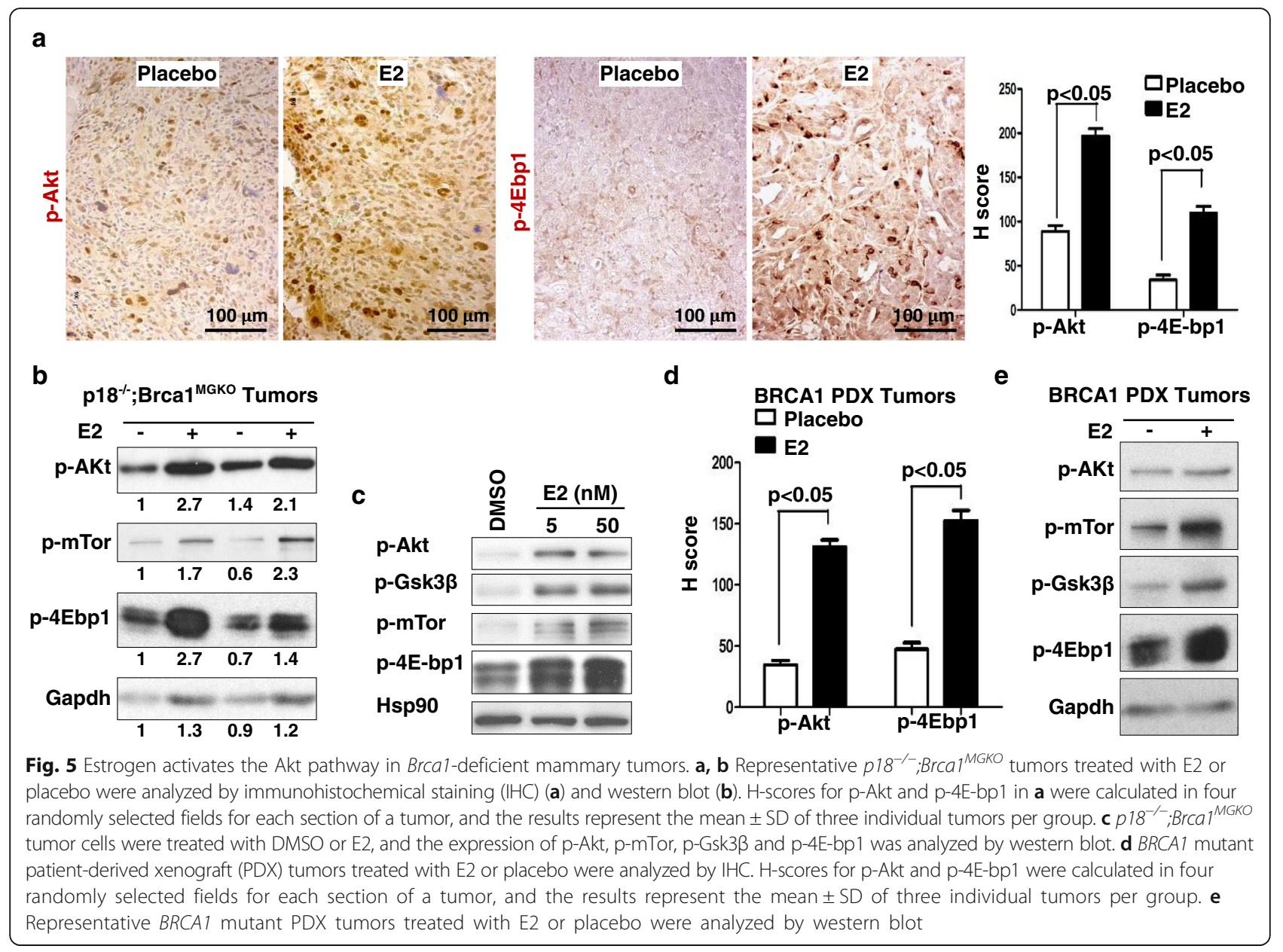

on Brca1-deficient cell proliferation and tumor progression. We treated $p 18^{-/-} ; B r c a 1^{M G K O}$ tumor cells with E2 in the presence or absence of AZD5363, a well-studied preclinical Akt inhibitor [50]. We found that AZD5363 drastically inhibited E2-enhanced expression of p-4Ebp1, p-mTor, and p-Gsk3ß, and that of Vim and p-Fra1 (Fig. 6a), suggesting that AZD5363 efficiently suppresses estrogen-enhanced Akt pathway and EMT program in Brca1 deficient tumor cells. Treatment of $\mathrm{p}^{-8^{-/}}$; Brcal $^{M G K O}$ tumor cells including both type 1 and type 2 cells with AZD5363 significantly reduced the E2enhanced number of cells and incorporation of BrdU (Fig. 6b, c and Additional file 8: Figure S8C), indicating that AZD5363 inhibits estrogen-enhanced proliferation of Brca1-deficient tumor cells.

We then determined if pharmaceutical inhibition of Akt activity suppresses the progression of pre-existing Brca1-deficient tumors. Transplanted $p 18^{-/-} ;$Brca $^{M G K O}$ tumors with E2 supplement were allowed to reach $\sim 250 \mathrm{~mm}^{3}$ in size and then mice were treated with vehicle or AZD5363 daily. Three days after treatment, tumors from AZD5363-treated mice began to show a significant size reduction in comparison with the tumors from vehicle-treated animals. After 7-day treatment, tumors from vehicle-treated mice reached $\sim 1475 \mathrm{~mm}^{3}$ in size, whereas those from AZD5363 -treated mice only reached $\sim 188 \mathrm{~mm}^{3}$, which was comparable with that of the tumor size at the start of treatment $\left(\sim 224 \mathrm{~mm}^{3}\right)$ $(p=0.59)$ (Fig. 6d), indicating that treatment with AZD5363 prevents estrogen-enhanced Brca1-deficient tumor progression.

Further analysis of tumors by IHC and western blot revealed that in tumors from mice with E2 supplement the expression of p-4Ebp1, p-mTor, and p-Gsk3 $\beta$ was clearly reduced by AZD5363 treatment relative to vehicle treatment (Fig. $6 \mathrm{e}$ and Additional file 8: Figure S8D), confirming the role of AZD5363 in inhibition of the estrogen-induced Akt pathway in Brca1-deficient tumor progression. Notably, the expression of Vim, Fn and Slug in tumors with E2 was drastically reduced and that of E-cad was enhanced in AZD5363-treated mice relative to control (Fig. 6e, f). These data demonstrate that AZD5363 efficiently suppresses estrogen-activated EMT in Brca1-deficient tumors in vivo. Consistent with the findings derived from $p 18^{-/-} ;$Brcal $^{M G K O}$ tumor cells in vitro (Fig. 6b), 


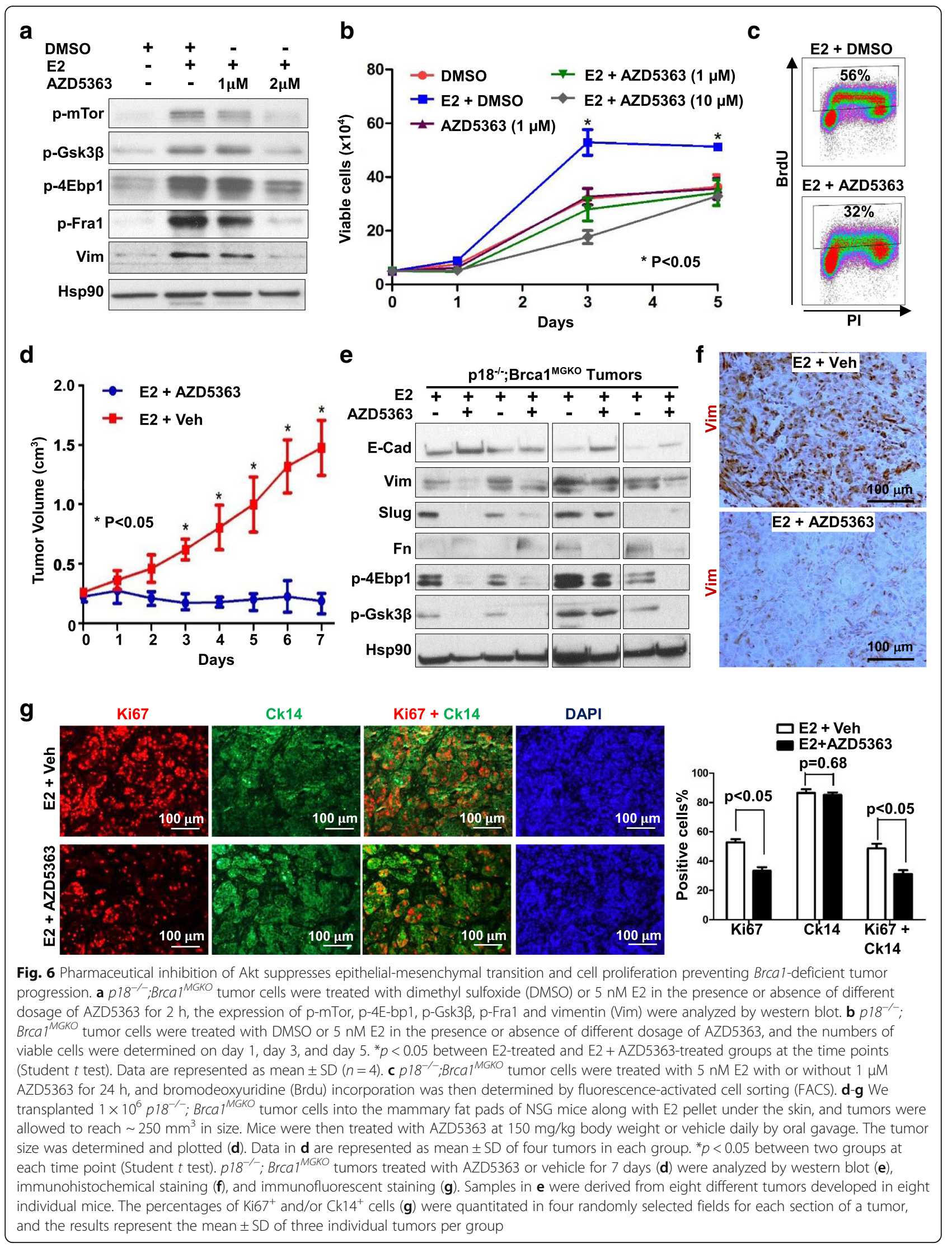


we also detected that AZD5363 significantly reduced the number of Ki67 and Ck14 double-positive cells stimulated by E2 in $p 18^{-/-} ; \mathrm{Brcal}^{\text {MGKO }}$ tumors (Fig. 6g). Together, these results indicate that estrogen promotes EMT and proliferation of Brca1-deficinet tumor cells leading to tumor progression, which is dependent on the activation of the Akt pathway.

\section{Discussion}

In this study, we found that deletion of Brca1 enhances the tumor-initiating potential of tumor cells, and that estrogen stimulates proliferation and the tumor-initiating potential of both Brca1-proficient ER-positive and Brca1deficient ER-negative tumor cells. We discovered that estrogen activates EMT in a subset of Brca1-deficient tumor cells that maintain epithelial features, and enhances the number of CSCs, promoting ER-negative basal-like tumor progression and metastasis. We found that estrogen activates EMT independent of ER in Brca1-deficient but not Brca1-proficient tumor cells. We further discovered that estrogen activates the Akt pathway in Brcal-deficient mammary tumor cells independent of ER, and that pharmaceutical inhibition of Akt activity suppresses EMT and cell proliferation preventing Brcal-deficient tumor progression. To the best of our knowledge, this study reveals for the first time that estrogen promotes BRCA1deficient tumor initiation and progression by stimulation of cell proliferation and activation of EMT, which are dependent on AKT activation and independent of ER.

It has long been known that estrogen is required for normal mammary development and that it promotes mammary tumorigenesis and progression [1, 2]. Not until recently has the role of estrogen in stimulation of normal and cancerous mammary stem cells been investigated. Though mammary stem cells lack the ER [43], they are highly responsive to estrogen [51]. Estrogen expands the number and promotes the function of mammary stem cells, likely mediated through paracrine signaling from RANK ligand produced in ER-positive luminal epithelial cells [51]. More recently, it has been reported that estrogen promotes mammary stem cells by paracrine signaling from IGF and WNT provided in stromal cells, in which Gli2 induces expression of ER and coordinates the induction of stem cell support factors including insulin-like growth factor (IGF) and WNT [52]. Interestingly, estrogen has been found to promote ER-negative breast CSCs derived from ER-positive cell lines through paracrine FGF-Tbx3, EGFR, and Notch signaling provided in ER-positive cells $[5,7,8]$. Notably, paracrine factors produced in response to estrogen in ER-positive cancer cells also expands CSCs derived from ER-negative breast cancer cell lines [7]. However, all of these findings on the role of estrogen in promoting breast CSCs were obtained from cell lines in vitro, and were dependent on the paracrine stem cell supporting and promoting factors that were provided by ER-positive cells. It remains elusive whether estrogen directly regulates breast CSCs in ER-negative breast cancers. We have previously reported that heterozygous germline deletion or mammary epithelial specific deletion of Brcal in mice promotes CSCs and induces development of ER-negative mammary tumors [19, 23, 39]. We report in this paper that estrogen enhances the number of breast CSCs in Brca1-deficient, ER-negative mammary tumors independent of ER. Our results indicate that BRCA1 deficiency caused by somatic mutation or promoter methylation of BRCA1 in sporadic ER-negative breast cancers sensitizes tumor cells to endogenous estrogen activating EMT, promoting CSCs and, therefore, inducing tumor progression. Our finding supports the development of strategies to inhibit estrogen synthesis for treatment of BRCA1-deficient BLBCs.

EMT plays a critical role in generating CSCs in tumor development and progression [12, 13]. The role of estrogen in regulation of EMT in breast cancer is controversial. On one hand, it is extensively studied and reported that estrogen activates ER $\alpha$ signaling, maintaining epithelial phenotype and suppressing EMT (as reviewed [53]), but on the other hand, estrogen has been found to activate EMT in ER-positive breast and ovarian cancer cells, promoting their stemness and invasiveness [5-7, 54]. Again, all the findings on promotion of EMT by estrogen were obtained from cancer cell lines and are dependent on activation of ER signaling. However, it remains obscure whether estrogen regulates EMT in ER-negative cancer cells and alters their properties in tumor initiation and progression. We showed that estrogen does not activate EMT in ER-positive and Brca1proficient tumor cells in vitro and tumorigenesis in vivo. These data warrant further investigation of the role of estrogen/ER signaling in regulation of EMT in tumorigenesis. Importantly, we demonstrated that estrogen activates EMT in a subset of ER-negative and Brca1-deficient mammary tumor cells, promoting their properties in tumor initiation and progression. These results provide the first genetic evidence demonstrating that estrogen activates EMT in ER-negative breast cancer cells independent of paracrine factors produced by ER-positive cells.

The PI3K/AKT pathway stimulates tumor development and progression through multiple mechanisms including promotion of cell proliferation, survival, and EMT $[25,26]$. Estrogen activates the PI3K/AKT pathway in ER-negative breast cancer cells, and promotes survival of Brca1deficient tumor cells, which stimulate tumor growth [30]. Estrogen also stimulates proliferation of Brca1-mutant cells through activation of remaining ER $\alpha$, which is gradually diminished during tumor progression in $\mathrm{Brcal}^{\Delta 11 / \Delta 11} \mathrm{p} 53^{+/-}$ 
mice [55]. Depletion or inhibition of the PI3K/Akt pathway reduces proliferation of $B R C A 1$-deficient MEFs suppressing growth of tumors generated by transplantation of BRCA1deficient MEFs [28]. However, it remains elusive whether estrogen stimulates proliferation of ER-negative BRCA1deficient tumor cells in vivo through activation of the Akt pathway. Further, due to the lack of a proper model system, i.e. ER-negative BRCA1-deficient tumor cells that can be induced by estrogen to EMT in vitro and in vivo, it is unknown if estrogen-activated EMT in ER negative BRCA1deficient tumor cells is dependent on AKT activation. In the present study, we demonstrated that estrogen activates the Akt pathway not only stimulating proliferation but also promoting EMT in ER-negative, BRCA1-deficient tumor cells, which further enhances tumor progression.

In this study, we investigated the effect of estrogen on ER-negative BRCA1-deficient tumor progression by transplantation of tumor cells into the MFPs of NSG mice that did not receive ovariectomy. Host estrogen in recipient mice may play a role in ER-negative BRCA1deficient tumor growth and progression. Transplantation of ER-positive $p 18^{-/-}$tumor cells into NSG mice did not produce tumors, whereas, with exogenous E2 supplement, $p 18^{-/-}$tumor cells generated ER-positive tumors in NSG mice, suggesting that host estrogen is not sufficient to induce $p 18$ deficient, Brcal-proficient tumor initiation. Notably, transplantation of either $p 18^{-/}$; Brcal $1^{M G K O}$ or $p 16^{-/-} ; B r c a 1^{M G K O}$ tumor cells into NSG mice generated tumors efficiently, which were further promoted by exogenous E2 administration. Taking into consideration our finding that estrogen promotes EMT, proliferation, sphere-forming potential, and Akt activation in Brca1-deficient tumor cells in vitro, these results suggest that host estrogen likely promotes Brca1-deficient tumor initiation, which support our conclusion. Importantly, it has been demonstrated that the E2 pellet $(0.72 \mathrm{mg}$ pellet) we used produces between 18 and 40 times higher concentrations of serum E2 than the physiological range in intact mice [56], suggesting that the effect of host estrogen on tumor growth in recipient mice is minor on supplementation with the E2 pellet. Furthermore, as estrogen is produced in the ovaries, adrenal glands, and fat tissues, an ovariectomy reduces only about $1 / 3$ of the serum E2 concentration in female mice when compared with the serum E2 concentration in mice with intact ovaries [57]. Whether the reduced host estrogen due to ovariectomy in recipient mice impacts Brca1deficient tumorigenesis remains elusive.

\section{Conclusions}

Our finding, for the first time, demonstrates that estrogen promotes BRCA1-deficient tumor initiation and progression by stimulation of cell proliferation and activation of EMT, which are dependent on AKT activation and independent of ER. This study not only reveals the molecular mechanisms underlying the role of estrogen in promoting development and progression of ER-negative basal-like breast cancers but also identifies a druggable AKT pathway that is activated by estrogen in BRCA1-deficient breast cancers. This investigation will support to develop strategies to inhibit estrogen synthesis and to target AKT for treatment of BRCA1-deficient basal-like breast cancers.

\section{Additional file}

\begin{abstract}
Additional file 1: Figure S1. Characterization of mammary tumors developed in mutant mice in Balb/cB6 mixed background. Representative mammary tumors spontaneously developed in $p 18^{-/} ;$Brca $^{\text {MGKO }}$, p16 $6^{-1} ;$ Brca $1^{M G K O}$ and $p 18^{-1}$ mice were immunostained with the antibodies indicated. The representative cells are enlarged in the insets.

Additional file 2: Figure S2. $p 18^{-/-} ; \mathrm{BrCa}^{\mathrm{MGKO}}$ and $p 16^{-1-} ; \mathrm{BrCa}^{\mathrm{MGKO}}$ tumor cells generate reproducible ER-negative Brca1-deficient mammary tumors. (A) A primary mammary tumor (donor tumor A) developed in a 15-

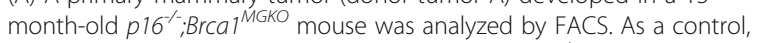
tumor-free mammary glands from age-matched $p 16^{-1-}$ mice were analyzed. Note a predominant $C D 24 ?^{+}$?CD29 $9^{\text {high }}$ population in the tumor. (B,

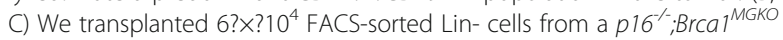
tumor (donor tumor B) into MFPs of four NSG mice. Representative tumors generated were analyzed by $I H C(B)$ and western blot $(C)$. (D, E) Representative $p 18^{-/}$and $p 18^{-/} ;$Brca $^{M G K O}$ tumor cells were cultured and analyzed. MCF7 cells were used as a positive control of ERa expression. (F, G) We transplanted $1 ? \times ? 10^{6}$ cultured $p 18^{-/} ;$Brcal $^{\text {MGKO }}$ tumor (donor tumor A) cells into MFPs of four NSG mice. Representative tumors generated were analyzed by $\mathrm{IHC}(\mathrm{F})$ and western blot (G). $p 18^{-/}$tumors were used as control in (C) and (G).
\end{abstract}

Additional file 3: Figure S3. Estrogen promotes Brca1-proficient and deficient mammary tumor initiation (A) Western blot analysis of mammary tumors regenerated by $p 18^{-/}$or $p 18^{-1-} ;$ Brca $^{M G K O}$ tumor cells with E2 supplement. (B) Representative gross pictures of $p 18^{-/-}$and p16 $6^{-1} ;$ Brca $^{\text {MGKO }}$ tumors generated by transplantation. We transplanted 1 $\times 10^{7} \mathrm{p}^{-1} 8^{-1}$ or $6 \times 10^{4} \mathrm{p}^{-16^{-}} ;$Brca $^{\text {MGKO }}$ tumor cells into MFPs of NSG mice with or without E2 supplement. Gross pictures were taken 6-7 weeks post-transplantation. (C) Representative H.E. staining of primary p $18^{-1-}$ tumors and tumors generated by $p 18^{-/}$tumor cells with E2 supplement. Note the well-differentiated cells with glandular structure in both primary and regenerated tumors. (D) Representative H.E. staining of

p16 $6^{-1} ;$ Brca $1^{M G K O}$ tumors generated in the presence or absence of E2 supplement. Note the poorly differentiated cells with increased fibroblastlike cells in the tumors with E2 treatment. Spindle cells (black arrows), cells with high nuclear-cytoplasm ratio (green arrows), mitotic cells (red arrows), and necrosis (yellow arrows) are indicated.

Additional file 4: Figure S4. Estrogen promotes lung metastasis of Brca1-deficient mammary tumors. (A, B) Metastatic p18 ${ }^{-1}$; Brca $1^{M G K O}$ tumor cells were inoculated into the MFPs of NSG mice with either E2 or placebo supplement. When newly generated tumors reached maximum size allowed by the IACUC in 3-6 weeks, or the mice became moribund, lungs were dissected for analysis. Representative gross pictures (A) and H.E. staining (B) of lungs are shown.

Additional file 5: Figure S5. $I H C$ analysis of ERa and EMT markers for tumors with or without E2 treatment. (A-C) Representative p18 $8^{-/} ;$Brca $^{M G K O}$ and $p 18^{-/}$mammary tumors treated with E2 or placebo were immunostained with the antibodies indicated. Note the negative ERa staining in E2-treated $p 18^{-/} ;$Brca $^{\text {MGKO }}$ tumors (B) and positive ERa staining in E2-treated $p 18^{-/}$tumors (C).

Additional file 6: Figure S6. Estrogen promotes EMT in Brca1-deficient tumor cells (A, B) p18 $8^{-/} ; \operatorname{Brcal}^{M G K O}$ type 1 (A) and $p 18^{--}$tumor cells (B) were treated with DMSO or E2 for the indicated time and analyzed by

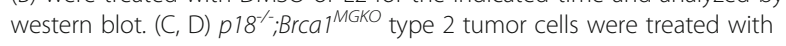


DMSO or $50 \mathrm{nM} \mathrm{E2} \mathrm{for} 2 \mathrm{~h}$ or $72 \mathrm{~h}$, and then analyzed by FACS (C) and western blot (D). (E) SUM149 cells were treated with DMSO or 50 nM E2 for $72 \mathrm{~h}$ and analyzed by western blot.

Additional file 7: Figure S7. Estrogen stimulates ER-positive cell proliferation that is blocked by $4 \mathrm{OHT}$. MCF-7 cells were treated with DMSO and $5 \mathrm{nM}$ E2 with or without $5 \mu \mathrm{M} 4 \mathrm{OHT}$. The number of viable cells was determined on day 1 , day 3 , and day 5 (A). Cells treated for $72 \mathrm{~h}$ were collected and analyzed by western blot (B); ${ }^{*} p ?<? 0.05$ between E2-treated and E2?+?4OHT-treated groups at the time points (Student $t$ test). Data are represented as mean?+?SD (n?=?4).

Additional file 8: Figure S8. E2 activates the AKT pathway in BRCA1 mutant PDX tumors, and inhibition of Akt suppresses proliferation of Brca1-deficient tumor cells. (A, B) Representative BRCA1 mutant PDX tumors treated with E2 or placebo were immunostained with the antibodies indicated. (C) $p 18^{-1} ;$ Brcal ${ }^{\text {MGKO }}$ type 2 tumor cells were treated with DMSO or $5 \mathrm{nM}$ E2 in the presence of different dosage of AZD5363. The number of viable cells were determined on day 1 , day 3 , and day 5 ; ${ }^{*} p ?<? 0.05$ between E2-treated and E2?+?AZD5363-treated groups at the time points (Student $t$ test). Data are represented as mean? \pm ?SD $(n ?=? 4)$. (D) Representative $p 18^{-\%} ;$ Brca $^{M G K O}$ tumors treated with AZD5363 or vehicle for 7 days were analyzed by IHC. (PDF 3678 kb)

\section{Abbreviations}

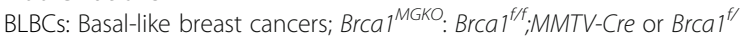
-:MMTV-Cre); BrdU: Bromodeoxyuridine; CSCs: Cancer stem cells; DMEM: Dulbecco's modified Eagle's medium; DMSO: Dimethyl sulfoxide; E2: 17ß-estradiol; E-cad: E-cadherin; EMT: Epithelial-mesenchymal transition; EMT-TFs: Epithelial-mesenchymal transition-inducing transcription factors; ER: Estrogen receptor; FACS: Fluorescence-activated cell sorting; FBS: Fetal bovine serum; Fn: Fibronectin; H.E.: Hematoxylin and eosin;

IACUC: Institutional Animal Care and Use Committee; IHC: Immunohistochemical analysis; INK4: Inhibitors of CDK4/6; MECs: Mammary epithelial cells; MEFs: Mouse embryonic fibroblasts; MFPs: Mammary fat pads; p16: p16 $6^{\text {lnk4a }}$; p18: p18 $8^{\text {Ink4c; }}$ PDX: Patient-derived xenografts; PI3K: Phosphatidylinositol-3-kinase; Vim: Vimentin

\section{Acknowledgements}

We thank Drs. Beverly Koller, Chuxia Deng, Norman Sharpless, and Lothar Hennighausen for Brcal mutant, p16 null, and MMTV-cre mice; Yue Xiong for discussion; Emely Pimentel for technical support; Jun-Zhu (Jenny) Pei for proofreading; the FACS core facility at University of Miami for cell sorting; and the DVR core facility for animal husbandry. Chuying Wang thanks Xi'an Jiaotong University for financial support.

\section{Funding}

This study was supported by DOD Idea Expansion Award (W81XWH-13-1-0282), the Woman's Cancer Association Grant, the Bankhead-Coley Cancer Research grant (TBC07), and research funds from the University of Miami Department of Surgery and Sylvester Comprehensive Cancer Center to Xin-Hai Pei.

\section{Availability of data and materials}

All data generated or analyzed during this study are included in this published article and its supplementary information files.

\section{Authors' contributions}

$\mathrm{CW}, \mathrm{FB}$, and XHP designed the research; $\mathrm{CW}, \mathrm{FB}$, and $\mathrm{LZ}$ performed the research; AS generated and characterized p 16;Brcal mice; CW, FB, and XHP analyzed the data; EL provided administrative, technical, and material support; CW, FB, and XHP wrote the paper; XHP provided financial support and supervised the project. All authors read and approved the final manuscript.

\section{Ethics approval}

The Institutional Animal Care and Use Committee at the University of Miami approved all animal procedures.

\section{Consent for publication}

Not applicable.

\section{Competing interests}

The authors declare that they have no competing interests.

\section{Publisher's Note}

Springer Nature remains neutral with regard to jurisdictional claims in published maps and institutional affiliations.

\section{Author details}

'Department of Medical Oncology, The First Affiliated hospital of Xi'an Jiaotong University, Xi'an, Shaanxi 710061, People's Republic of China. ${ }^{2}$ Molecular Oncology Program, Division of Surgical Oncology, Dewitt Daughtry Family Department of Surgery, University of Miami, Miami, FL 33136, USA. 'Sylvester Comprehensive Cancer Center, Miller School of Medicine, University of Miami, Miami, FL 33136, USA.

Received: 20 February 2018 Accepted: 30 May 2018

Published online: 11 July 2018

\section{References}

1. Yue W, Yager JD, Wang JP, Jupe ER, Santen RJ. Estrogen receptordependent and independent mechanisms of breast cancer carcinogenesis. Steroids. 2013;78:161-70

2. Dall GV, Britt KL. Estrogen effects on the mammary gland in early and late life and breast cancer risk. Front Oncol. 2017;7:110.

3. Swain SM. Tamoxifen for patients with estrogen receptor-negative breast cancer. J Clin Oncol. 2001;19:93S-7S.

4. Rebbeck TR, Kauff ND, Domchek SM. Meta-analysis of risk reduction estimates associated with risk-reducing salpingo-oophorectomy in BRCA1 or BRCA2 mutation carriers. J Natl Cancer Inst. 2009;101:80-7.

5. Sun Y, Wang Y, Fan C, Gao P, Wang X, Wei G, Wei J. Estrogen promotes stemness and invasiveness of ER-positive breast cancer cells through Gli1 activation. Mol Cancer. 2014;13:137.

6. Planas-Silva MD, Waltz PK. Estrogen promotes reversible epithelial-tomesenchymal-like transition and collective motility in MCF-7 breast cancer cells. J Steroid Biochem Mol Biol. 2007;104:11-21.

7. Fillmore CM, Gupta PB, Rudnick JA, Caballero S, Keller PJ, Lander ES, Kuperwasser C. Estrogen expands breast cancer stem-like cells through paracrine FGF/Tbx3 signaling. Proc Natl Acad Sci U S A. 2010;107:21737-42.

8. Harrison H, Simoes BM, Rogerson L, Howell SJ, Landberg G, Clarke RB. Oestrogen increases the activity of oestrogen receptor negative breast cancer stem cells through paracrine EGFR and notch signalling. Breast Cancer Res. 2013:15:R21.

9. Koboldt DC, Fulton RS, McLellan MD, Schmidt H, Kalicki-Veizer J, McMichael JF, Fulton LL, Dooling DJ, Ding L, Mardis ER, et al. Comprehensive molecular portraits of human breast tumours. Nature. 2012;487:330-7.

10. Fedele M, Cerchia L, Chiappetta G. The epithelial-to-mesenchymal transition in breast cancer: focus on basal-like carcinomas. Cancers (Basel). 2017;9(10); 134.

11. Wicha MS. Cancer stem cell heterogeneity in hereditary breast cancer. Breast Cancer Res. 2008;10:105.

12. Ye X, Weinberg RA. Epithelial-mesenchymal plasticity: a central regulator of cancer progression. Trends Cell Biol. 2015;25:675-86.

13. Mani SA, Guo W, Liao MJ, Eaton EN, Ayyanan A, Zhou AY, Brooks M, Reinhard F, Zhang CC, Shipitsin M, et al. The epithelial-mesenchymal transition generates cells with properties of stem cells. Cell. 2008;133:704-15.

14. Kim MJ, Ro JY, Ahn SH, Kim HH, Kim SB, Gong G. Clinicopathologic significance of the basal-like subtype of breast cancer: a comparison with hormone receptor and Her2/neu-overexpressing phenotypes. Hum Pathol. 2006:37:1217-26.

15. Livasy CA, Karaca G, Nanda R, Tretiakova MS, Olopade Ol, Moore DT, Perou CM. Phenotypic evaluation of the basal-like subtype of invasive breast carcinoma. Mod Pathol. 2006;19:264-71.

16. Lim E, Vaillant F, Wu D, Forrest NC, Pal B, Hart AH, Asselin-Labat ML, Gyorki $D E$, Ward T, Partanen A, et al. Aberrant luminal progenitors as the candidate target population for basal tumor development in BRCA1 mutation carriers. Nat Med. 2009;15:907-13.

17. Proia TA, Keller PJ, Gupta PB, Klebba I, Jones AD, Sedic M, Gilmore H, Tung N, Naber SP, Schnitt S, et al. Genetic predisposition directs breast cancer phenotype by dictating progenitor cell fate. Cell Stem Cell. 2011;8:149-63.

18. Molyneux G, Geyer FC, Magnay FA, McCarthy A, Kendrick H, Natrajan R, Mackay A, Grigoriadis A, Tutt A, Ashworth A, et al. BRCA1 basal-like breast cancers originate from luminal epithelial progenitors and not from basal stem cells. Cell Stem Cell. 2010;7:403-17. 
19. Bai F, Smith MD, Chan HL, Pei XH. Germline mutation of Brca1 alters the fate of mammary luminal cells and causes luminal-to-basal mammary tumor transformation. Oncogene. 2013;32:2715-25.

20. De Summa S, Pinto R, Sambiasi D, Petriella D, Paradiso V, Paradiso A Tommasi S. BRCAness: a deeper insight into basal-like breast tumors. Ann Oncol. 2013;24(Suppl 8):viii13-21.

21. Zhu X, Shan L, Wang F, Wang J, Wang F, Shen G, Liu X, Wang B, Yuan Y, Ying J, Yang H. Hypermethylation of BRCA1 gene: implication for prognostic biomarker and therapeutic target in sporadic primary triple-negative breast cancer. Breast Cancer Res Treat. 2015;150:479-86.

22. Liu X, Holstege $H$, van der Gulden H, Treur-Mulder M, Zevenhoven J, Velds A, Kerkhoven RM, van Vliet MH, Wessels LF, Peterse JL, et al. Somatic loss of BRCA 1 and p53 in mice induces mammary tumors with features of human BRCA1-mutated basal-like breast cancer. Proc Natl Acad Sci U S A. 2007;104: 12111-6.

23. Bai F, Chan HL, Scott A, Smith MD, Fan C, Herschkowitz Jl, Perou CM, Livingstone AS, Robbins DJ, Capobianco AJ, Pei XH. BRCA1 suppresses epithelial-to-mesenchymal transition and stem cell dedifferentiation during mammary and tumor development. Cancer Res. 2014;74:6161-72.

24. Rodriguez-Pinilla SM, Sarrio D, Honrado E, Moreno-Bueno G, Hardisson D, Calero F, Benitez J, Palacios J. Vimentin and laminin expression is associated with basal-like phenotype in both sporadic and BRCA1-associated breast carcinomas. J Clin Pathol. 2007;60:1006-12.

25. Xu W, Yang Z, Lu N. A new role for the PI3K/Akt signaling pathway in the epithelial-mesenchymal transition. Cell Adhes Migr. 2015;9:317-24.

26. Yang SX, Polley E, Lipkowitz S. New insights on PI3K/AKT pathway alterations and clinical outcomes in breast cancer. Cancer Treat Rev. 2016; 45:87-96.

27. Yu JS, Cui W. Proliferation, survival and metabolism: the role of PI3K/AKT/ mTOR signalling in pluripotency and cell fate determination. Development. 2016;143:3050-60.

28. Xiang T, Jia Y, Sherris D, Li S, Wang H, Lu D, Yang Q. Targeting the Akt/ mTOR pathway in Brca1-deficient cancers. Oncogene. 2011;30:2443-50.

29. Xiang T, Ohashi A, Huang Y, Pandita TK, Ludwig T, Powell SN, Yang Q. Negative regulation of AKT activation by BRCA1. Cancer Res. 2008;68:10040-4.

30. Gorrini C, Gang BP, Bassi C, Wakeham A, Baniasadi SP, Hao Z, Li WY, Cescon DW, Li YT, Molyneux S, et al. Estrogen controls the survival of BRCA1deficient cells via a PI3K-NRF2-regulated pathway. Proc Natl Acad Sci U S A. 2014;111:4472-7.

31. Renoir JM, Marsaud V, Lazennec G. Estrogen receptor signaling as a target for novel breast cancer therapeutics. Biochem Pharmacol. 2013;85:449-65.

32. Pei XH, Xiong Y. Biochemical and cellular mechanisms of mammalian CDK inhibitors: a few unresolved issues. Oncogene. 2005;24:2787-95.

33. Jonsson G, Staaf J, Vallon-Christersson J, Ringner M, Gruvberger-Saal SK, Saa LH, Holm K, Hegardt C, Arason A, Fagerholm R, et al. The retinoblastoma gene undergoes rearrangements in BRCA1-deficient basal-like breast cancer. Cancer Res. 2012;72:4028-36.

34. Stefansson OA, Jonasson JG, Olafsdottir K, Hilmarsdottir H, Olafsdottir G, Esteller M, Johannsson OT, Eyfjord JE. CpG island hypermethylation of BRCA1 and loss of pRb as co-occurring events in basal/triple-negative breast cancer. Epigenetics. 2011;6:638-49.

35. Hollestelle A, Nagel JH, Smid M, Lam S, Elstrodt F, Wasielewski M, Ng SS, French PJ, Peeters JK, Rozendaal MJ, et al. Distinct gene mutation profiles among luminal-type and basal-type breast cancer cell lines. Breast Cancer Res Treat. 2010;121:53-64.

36. Stephens PJ, McBride DJ, Lin ML, Varela I, Pleasance ED, Simpson JT, Stebbings LA, Leroy C, Edkins S, Mudie LJ, et al. Complex landscapes of somatic rearrangement in human breast cancer genomes. Nature. 2009;462:1005-10.

37. Pei XH, Bai F, Smith MD, Usary J, Fan C, Pai SY, Ho IC, Perou CM, Xiong Y. CDK inhibitor p18(INK4C) is a downstream target of GATA3 and restrains mammary luminal progenitor cell proliferation and tumorigenesis. Cancer Cell. 2009;15:389-401.

38. Jiang Z, Deng T, Jones R, Li H, Herschkowitz JI, Liu JC, Weigman VJ, Tsao MS, Lane TF, Perou CM, Zacksenhaus E. Rb deletion in mouse mammary progenitors induces luminal-B or basal-like/EMT tumor subtypes depending on p53 status. J Clin Invest. 2010;120:3296-309.

39. Scott A, Bai F, Chan HL, Liu S, Ma J, Slingerland JM, Robbins DJ, Capobianco AJ, Pei XH. p16INK4a suppresses BRCA1-deficient mammary tumorigenesis. Oncotarget. 2016;7:84496-507.

40. Sedic M, Skibinski A, Brown N, Gallardo M, Mulligan P, Martinez P, Keller PJ, Glover E, Richardson AL, Cowan J, et al. Haploinsufficiency for BRCA1 leads to cell-type-specific genomic instability and premature senescence. Nat Commun. 2015:6:7505.

41. Goulding H, Pinder S, Cannon P, Pearson D, Nicholson R, Snead D, Bell J, Elston CW, Robertson JF, Blamey RW, et al. A new immunohistochemical antibody for the assessment of estrogen receptor status on routine formalin-fixed tissue samples. Hum Pathol. 1995;26:291-4.

42. Visvader JE, Stingl J. Mammary stem cells and the differentiation hierarchy: current status and perspectives. Genes Dev. 2014;28:1143-58.

43. Asselin-Labat ML, Shackleton M, Stingl J, Vaillant F, Forrest NC, Eaves CJ, Visvader JE, Lindeman GJ. Steroid hormone receptor status of mouse mammary stem cells. J Natl Cancer Inst. 2006:98:1011-4.

44. Hassanein M, Huiart L, Bourdon V, Rabayrol L, Geneix J, Nogues C, Peyrat JP, Gesta $\mathrm{P}$, Meynard P, Dreyfus $\mathrm{H}$, et al. Prediction of BRCA1 germ-line mutation status in patients with breast cancer using histoprognosis grade, MS110, Lys27H3, vimentin, and KI67. Pathobiology. 2013;80:219-27.

45. Dumont N, Wilson MB, Crawford YG, Reynolds PA, Sigaroudinia M, TIsty TD. Sustained induction of epithelial to mesenchymal transition activates DNA methylation of genes silenced in basal-like breast cancers. Proc Natl Acad Sci U S A. 2008;105:14867-72.

46. Turner NC, Reis-Filho JS, Russell AM, Springall RJ, Ryder K, Steele D, Savage K, Gillett CE, Schmitt FC, Ashworth A, Tutt AN. BRCA1 dysfunction in sporadic basal-like breast cancer. Oncogene. 2007;26:2126-32.

47. Gupta PB, Fillmore CM, Jiang G, Shapira SD, Tao K, Kuperwasser C, Lander ES. Stochastic state transitions give rise to phenotypic equilibrium in populations of cancer cells. Cell. 2011;146:633-44.

48. Prat A, Parker JS, Karginova O, Fan C, Livasy C, Herschkowitz II, He X, Perou CM. Phenotypic and molecular characterization of the claudin-low intrinsic subtype of breast cancer. Breast Cancer Res. 2010;12:R68.

49. Jordan NV, Prat A, Abell AN, Zawistowski JS, Sciaky N, Karginova OA, Zhou B, Golitz BT, Perou CM, Johnson GL. SWI/SNF chromatin-remodeling factor Smarcd3/Baf60c controls epithelial-mesenchymal transition by inducing Wnt5a signaling. Mol Cell Biol. 2013;33:3011-25.

50. Hyman DM, Smyth LM, Donoghue MTA, Westin SN, Bedard PL, Dean EJ, Bando $H$, El-Khoueiry AB, Perez-Fidalgo JA, Mita A, et al. AKT inhibition in solid tumors with AKT1 mutations. J Clin Oncol. 2017;35:2251-9.

51. Asselin-Labat ML, Vaillant F, Sheridan JM, Pal B, Wu D, Simpson ER, Yasuda H, Smyth GK, Martin TJ, Lindeman GJ, Visvader JE. Control of mammary stem cell function by steroid hormone signalling. Nature. 2010;465:798-802.

52. Zhao C, Cai S, Shin K, Lim A, Kalisky T, Lu WJ, Clarke MF, Beachy PA. Stromal Gli2 activity coordinates a niche signaling program for mammary epithelial stem cells. Science. 2017;356:eaal3485.

53. Guttilla IK, Adams BD, White BA. ERalpha, microRNAs, and the epithelialmesenchymal transition in breast cancer. Trends Endocrinol Metab. 2012;23: 73-82.

54. Park SH, Cheung LW, Wong AS, Leung PC. Estrogen regulates snail and Slug in the down-regulation of E-cadherin and induces metastatic potential of ovarian cancer cells through estrogen receptor alpha. Mol Endocrinol. 2008; 22:2085-98.

55. Li W, Xiao C, Vonderhaar BK, Deng CX. A role of estrogen/ERalpha signaling in BRCA1-associated tissue-specific tumor formation. Oncogene. 2007;26: 7204-12.

56. Ingberg E, Theodorsson A, Theodorsson E, Strom JO. Methods for long-term 17beta-estradiol administration to mice. Gen Comp Endocrinol. 2012;175: 188-93.

57. Haisenleder DJ, Schoenfelder AH, Marcinko ES, Geddis LM, Marshall JC. Estimation of estradiol in mouse serum samples: evaluation of commercial estradiol immunoassays. Endocrinology. 2011;152:4443-7. 